\title{
苏鲁造山带威海泥质麻粒岩古元古代麻粒岩相 变质作用和三叠纪流体改造的独居石记录
}

\author{
熊志武, 续海金", 王攀, 章军锋 \\ 中国地质大学地球科学学院, 武汉 430074 \\ * 通讯作者, E-mail: xuhaijin@cug.edu.cn
}

收稿日期: 2020-09-27; 收修改稿日期: 2020-12-01; 接受日期: 2021-01-06; 网络版发表日期: 2021-04-13

国家自然科学基金项目(批准号: 42072058、41772054、41572039)资助

摘要独居石是苏鲁造山带威海地区出露的泥质麻粒岩中非常重要的一种副矿物, 也是用来探究麻粒岩变质演 化的有力工具. 威海地区的泥质麻粒岩呈透镜体状不协调地产出于花岗质片麻岩中. 透镜体从核部到边部, 岩性 逐渐变化, 依次为: 未变形的粗粒泥质麻粒岩、面理化的细粒泥质麻粒岩、石榴石黑云母片麻岩和混合岩化麻粒 岩。透镜体的核部保存有麻粒岩相峰期变质矿物组合: 石榴石十斜长石(反条纹长石) +石英十矽线石十黑云母，以及 副矿物金红石、锆石和独居石. 而透镜体的边部则出现受流体改造形成的退变质组合. 为了揭示该泥质麻粒岩透 镜体的变质演化过程, 文章对其中的独居石矿物进行了 BSE成图、U-Pb定年和微量元素成分的综合研究. 未变形 的粗粒泥质麻粒岩中独居石只记录了古元古代的年龄 $(1832 \pm 7) \mathrm{Ma}(n=40)$, 而其他三种岩石中的独居石则记录有 古元古代继承年龄和三叠纪新生年龄。例如，混合岩中的独居石 U-Pb定年结果给出(1818 \pm 10$) \mathrm{Ma}$ 的上交点年龄、 $(211 \pm 22) \mathrm{Ma}(n=56)$ 的下交点年龄以及 $(223.8 \pm 2.9) \mathrm{Ma}$ 的三叠纪谐和年龄. 在微量元素特征上, 古元古代独居石具有 强烈HREE和 $\mathrm{Y}$ 的亏损以及明显的Eu负异常，表明这些独居石是和石榴石及长石在麻粒岩相条件下同期生长的. 而在三叠纪流体改造过程中，独居石边部获得 Th和 $\mathrm{Si}$ 元素而释放出U、HREE、Y和 $\mathrm{P}$, 该过程使得三叠纪增生独 居石具有更高的HREE和 Y含量、低的 Th和U的含量及相对低的 $\mathrm{Th} / \mathrm{U}$ 比值. 因此，泥质麻粒岩中的独居石记录了 古元古代的麻粒岩相的变质作用和三叠纪的流体改造过程. 威海地区泥质麻粒岩在构造属性上可能属于华北克 拉通, 在三叠纪的大陆碰撞过程中被卷入苏鲁造山带, 并在之后折返过程中受到了流体的改造.

关键词 泥质麻粒岩, 独居石, 古元古代, 三叠纪, 苏鲁造山带

\section{1 引言}

锆石和独居石是变质岩中非常重要的两种副矿 物, 由于其具有高的U和 Th含量、高的U-Th-Pb同位素
体系封闭温度以及非常低的 $\mathrm{Pb}$ 扩散率特征而被广泛 用于重建高级变质地体的时代(Cherniak和Watson, 2001; Cherniak等, 2004; McFarlane和Harrison, 2006). 与锆石相比，独居石对温度变化和熔、流体活动更加

\footnotetext{
中文引用格式: 熊志武, 续海金, 王攀, 章军锋. 2021. 苏鲁造山带威海泥质麻粒岩古元古代麻粒岩相变质作用和三叠纪流体改造的独居石记录. 中国科学: 地 球科学, 51(6): 884-905, doi: 10.1360/N072020-0335

英文引用格式: Xiong Z, Xu H, Wang P, Zhang J. 2021. Monazite recorded Paleoproterozoic granulite-facies metamorphism and Triassic fluid modification of the Weihai pelitic granulite, Sulu orogen. Science China Earth Sciences, 64(6): 932-950, https://doi.org/10.1007/s11430-020-9717-2
} 
敏感，在从角闪岩相到麻粒岩相变质条件下易生长或 者是发生重结晶(Rubatto等，2001; Williams等，2007; Taylor等, 2014; Johnson等, 2015; Guergouz等, 2018). 大量研究表明独居石在高级变质作用中的行为也与一 些关键变质矿物(如石榴石、钾长石和锆石)的形成或 分解有关(Foster等, 2002; Hermann和Rubatto, 2003; Buick等, 2010; Jiao等, 2013; Dumond等, 2015). 此外, 由于独居石中 $U$ 、 $\mathrm{Th}$ (及 $\mathrm{Th} / \mathrm{U}$ 比值)、HREE、Y和其他 一些关键元素含量的变化, 在BSE图中常可以观察到 独居石具有分带结构(Zhu和O'Nions，1999a；Kelly等， 2012; Bhowmik等, 2014; Taylor等, 2014; Xu等, 2019; Weinberg等, 2020). 然而, 在高级变质岩中这些具有分 带结构的独居石的成因机制却非常复杂. 早期碎屑独 居石的部分溶解及之后的再生长(Rasmussen等, 2007; Lasalle等, 2014; Wang等, 2017), 独居石的幕式生长 (Mottram等, 2014; Johnson等, 2015), 以及流体作用导 致原有独居石被改造, 是形成具有分带结构独居石的 三种主要方式. 越来越多的天然样品研究以及实验研 究结果表明, 受到流体改造的独居石, 其 $\mathrm{Th} 、 \mathrm{Si}$ 、 $\mathrm{Ca} 、 \mathrm{P}$ 和(Y+HREE)元素会被重新分配, 同时独居石的 U-Th-Pb同位素体系也会被部分或者完全重置(Zhu和 O’Nions, 1999a; Seydoux-Guillaume等, 2002; Harlov等, 2011; Williams等, 2011; Kelly等, 2012; Taylor等, 2014). 因此, 独居石不仅可以提供比锆石更多的年龄信息, 其 生长也蕴藏着构造热演化过程的重要信息.

苏鲁造山带形成于扬子板块和华北板块在三叠纪 时发生的大陆俯冲-碰撞作用, 是一个典型的陆-陆碰 撞造山带(从柏林和王清晨, 1999; Ernst等, 2007; Zheng, 2008; Liu和Liou, 2011). 大量研究表明, 造山 带内的变质岩(如榴辉岩)及其围岩(正片麻岩)均经历 了深俯冲作用、超高压变质作用和之后折返过程中的 深熔作用(例如, Zheng, 2008; Liu和Liou, 2011; Xu等, 2013). 近年来, 在苏鲁造山带中呈块状或是透镜体状 产出于正片麻岩中的泥质麻粒岩受到了广泛的关注 (Xu等, 2019; 熊志武等, 2021). 相平衡模拟、锆石 $\mathrm{Ti}$ 含 量温度计以及锆石 $\mathrm{U}-\mathrm{Pb}$ 年代学的研究表明, 这些泥质 麻粒岩经历了古元古代高温/超高温麻粒岩相变质作 用(Lei等, 2014; Xiang等, 2014; Xu等, 2019; 熊志武等, 2021). 然而, 这些泥质麻粒岩的变质演化过程和构造 亲属性仍是不清楚的.

本文以苏鲁造山带威海花岗质片麻岩中出露的泥
质麻粒岩透镜体为研究对象. 泥质麻粒岩透镜体从核 部到边部, 岩性逐渐变化, 依次出现未变形的粗粒泥 质麻粒岩、面理化的细粒泥质麻粒岩、石榴石黑云母 片麻岩以及混合岩化麻粒岩(熊志武等, 2021). 对上述 四类岩石中的独居石矿物开展了BSE成像、LA-ICP$\mathrm{MS}$ 和U-Pb定年以及微量元素成分的综合研究. 泥质 麻粒岩中的独居石呈现出受到流体改造的结构特征 (分带结构), 相应地伴随着化学成分的变化. U-Pb同位 素结果也表明了一次古元古代的变质事件 $(1.82 \mathrm{Ga})$ 和三叠纪(223.8 2 2.9) Ma流体作用下的独居石生长事 件. 因此, 本文的研究为理解泥质麻粒岩的变质演化过 程和厘定其构造亲属性提供了重要的制约.

\section{2 地质背景和样品描述}

大别-苏鲁造山带形成于三叠纪扬子克拉通和华 北克拉通之间发生的大陆深俯冲-碰撞作用, 以超高压 变质作用的广泛发育而闻名于世 $(\mathrm{Xu}$ 等，1992，2003; Ames等, 1996; Ye等, 2000a, 2000b). 苏鲁造山带位于 大别-苏鲁造山带的东段, 其与大别造山带被NNE向的 郯庐断裂所分隔, 并沿着断裂带向北位移近 $500 \mathrm{~km}$ (Zheng, 2008; Feng等, 2020). 苏鲁造山带之内又被数 条NE向的断层分割成若干个块体, 在这些断层中, 五 莲-烟台断裂和嘉山-响水断裂分别作为苏鲁造山带向 北与华北克拉通和向南与扬子克拉通的界限(图 1a). 苏鲁造山带中的主体岩性是正片麻岩, 这些正片麻岩 具有新元古代的原岩年龄, 其原岩成因与罗迪尼亚超 大陆裂解时扬子克拉通北缘发生的岩浆作用有关(Liu 等, 2004; Tang等, 2008; Zhang等, 2009; Xu等, 2013; 续 海金等, 2013). 这些正片麻岩也记录有三叠纪的变质 年龄, 加之三叠纪变质锆石含有柯石英包裹体, 表明正 片麻岩在三叠纪之时经历了超高压变质作用( $\mathrm{Ye}$ 等, 2000b; Liu等, 2001，2004). 其他一些少量的超高压变 质岩, 诸如榴辉岩、大理岩、泥质片岩以及石榴石橄 榄岩则呈分散的块状或透镜体状出露于花岗质片麻岩 中(Zhang等, 1994; Kato等, 1997; Ye等, 2000a; Yang等, 2003; Liu等, 2008). 此外, 苏鲁造山带被中生代火山碎 屑岩及新生代盖层所覆盖, 并且发育有中生代花岗岩 侵入体(Zhang等, 2010).

本文以苏鲁超高压地体威海地区出露的泥质麻粒 岩为研究对象 (图1a). 所研究的泥质麻粒岩以透镜体 


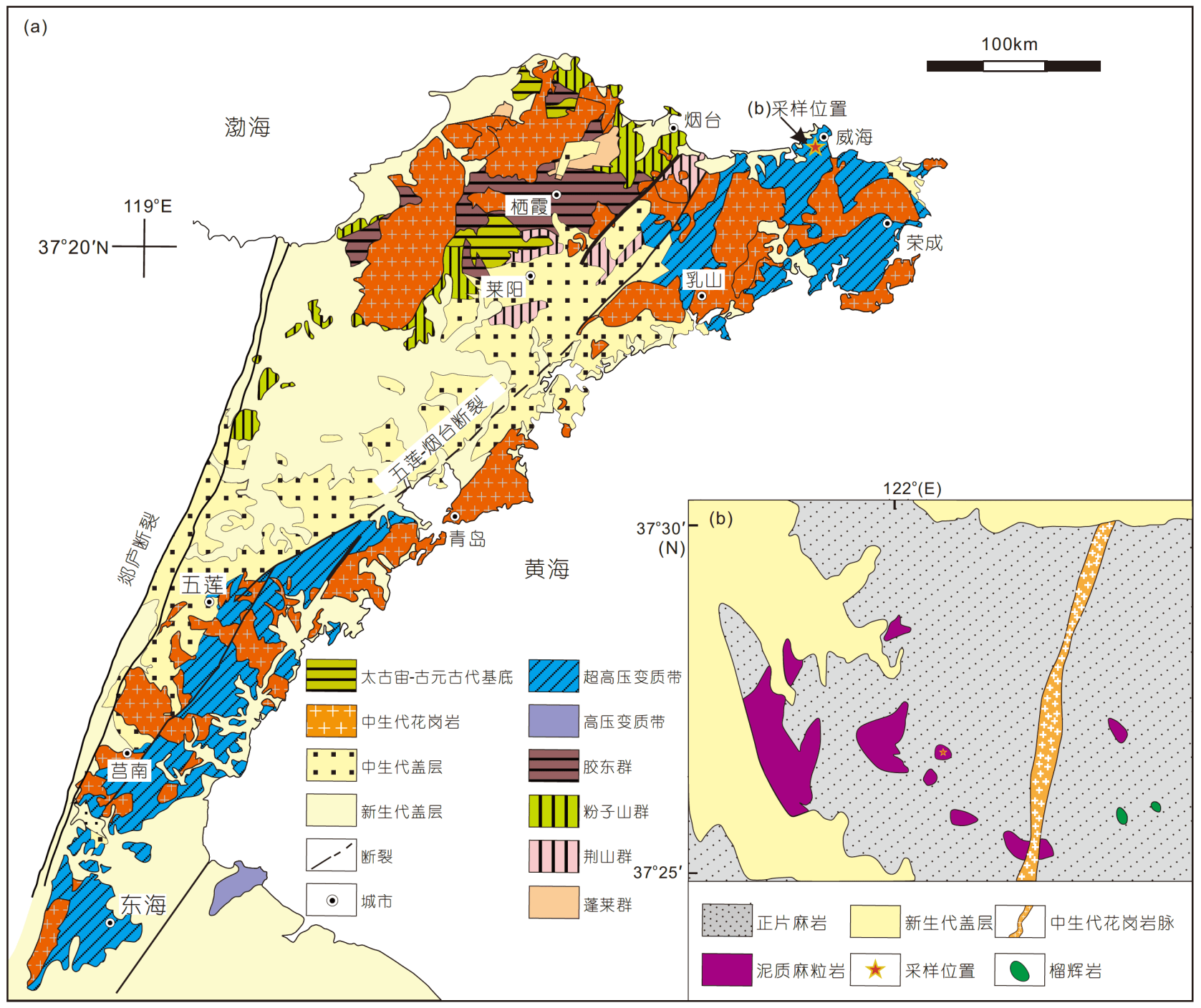

图 1 地质简图和采样点示意图

(a) 苏鲁造山带地质简图, 据Xiang等(2014)修改; (b) 威海地区采样位置, 据Xu等(2019)修改

状或布丁状产出于花岗质片麻岩之中(图1b). 围岩花 岗质片麻岩因在三叠纪折返过程中发生深熔作用而呈 现出不同程度的混合岩化(例如, Wallis等, 2005; 刘福 来等, 2009; Liu等, 2010, 2012; Zong等, 2010; Xu等, 2012, 2013; Chen等, 2013; Song等，2014; 高名迪等, 2018). 从泥质麻粒岩透镜体的核部到其边部可以划分 出四类不同的岩性：未变形的粗粒泥质麻粒岩、面理 化的细粒泥质麻粒岩、石榴石黑云母片麻岩和混合岩 化麻粒岩(图2a 2e). 根据泥质麻粒岩透镜体表现出的 岩性变化特征，相应地采集了四种岩石，具体的岩相
学描述如下.

未变形的麻粒岩(17WH-1, 图2b)为粗粒斑状变晶 结构, 主要矿物为石榴石 $(\sim 15 \%)$ 、斜长石(反条纹长 石) $(\sim 50 \%)$ 、石英 $(\sim 25 \%)$ 、黑云母( $8 \%)$ 、矽线石 $(\sim 2 \%)$ 以及少量的金红石、钛铁矿、锆石和独居石. 变 斑晶石榴石含有石英、斜长石、金红石、锆石和独居 石包裹体(图3a、3b). 黑云母呈冠状围绕石榴石生长, 或是呈脉状填充石榴石的裂隙(图3a). 部分斜长石为 反条纹长石, 可见有叶片状的钾长石出溶体 (图3c). 面 理化的麻粒岩(17WH-2, 图2c)为细粒变晶结构, 发育 


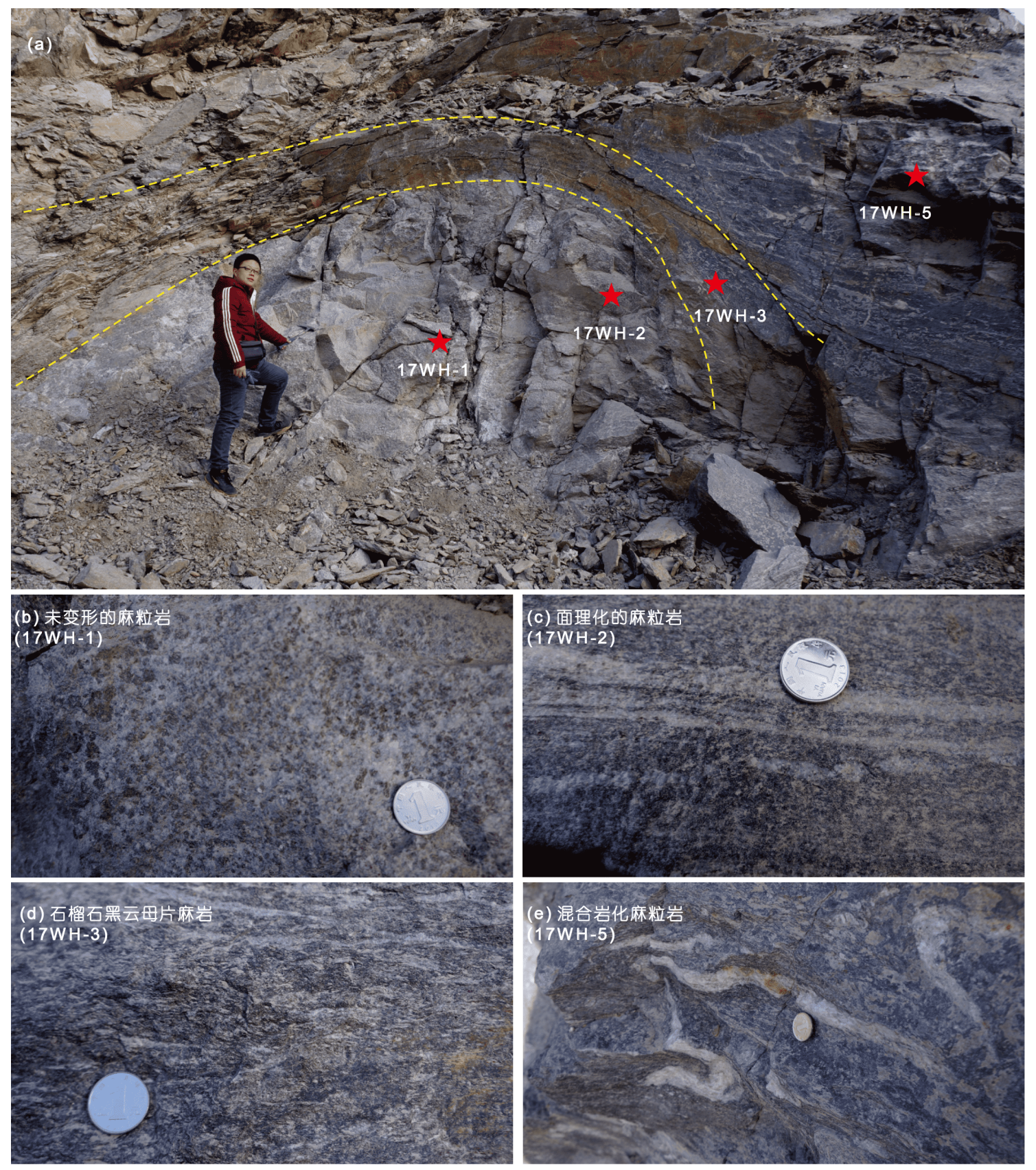

图 2 苏鲁造山带威海泥质麻粒岩野外露头及手标本照片

(a) 泥质麻粒岩透镜体野外照片; (b) (e) 泥质麻粒岩、石榴石黑云母片麻岩和混合岩化麻粒岩手标本照片

弱的面理, 主要矿物为石榴石 $(10 \%)$ 、斜长石(反条纹 长石) $(\sim 40 \%)$ 、石英 $(\sim 30 \%)$ 、黑云母 $(\sim 15 \%)$ 和矽线石 $(\sim 5 \%)$. 石榴石中可见斜长石、石英及金红石、锆石和 独居石包裹体(图3d)，石榴石周围常发育有黑云母的 冠状集合体，部分石榴石则被黑云母替代成残余体(图 3e). 基质中的黑云母和矽线石具有弱的定向性(图 3d 3f). 石榴石黑云母片麻岩(17WH-3, 图2d)主要矿物 包括黑云母 $(\sim 50 \%)$ 、石榴石 $(\sim 8 \%)$ 、斜长石及反条纹 长石 $(20 \%)$ 、石英 $(\sim 20 \%)$ 和矽线石 $(\sim 1 \sim 2 \%)$. 黑云母 和纤维状矽线石具有很强的定向性(图3 $\mathrm{g} 、 3 \mathrm{~h})$. 基质 


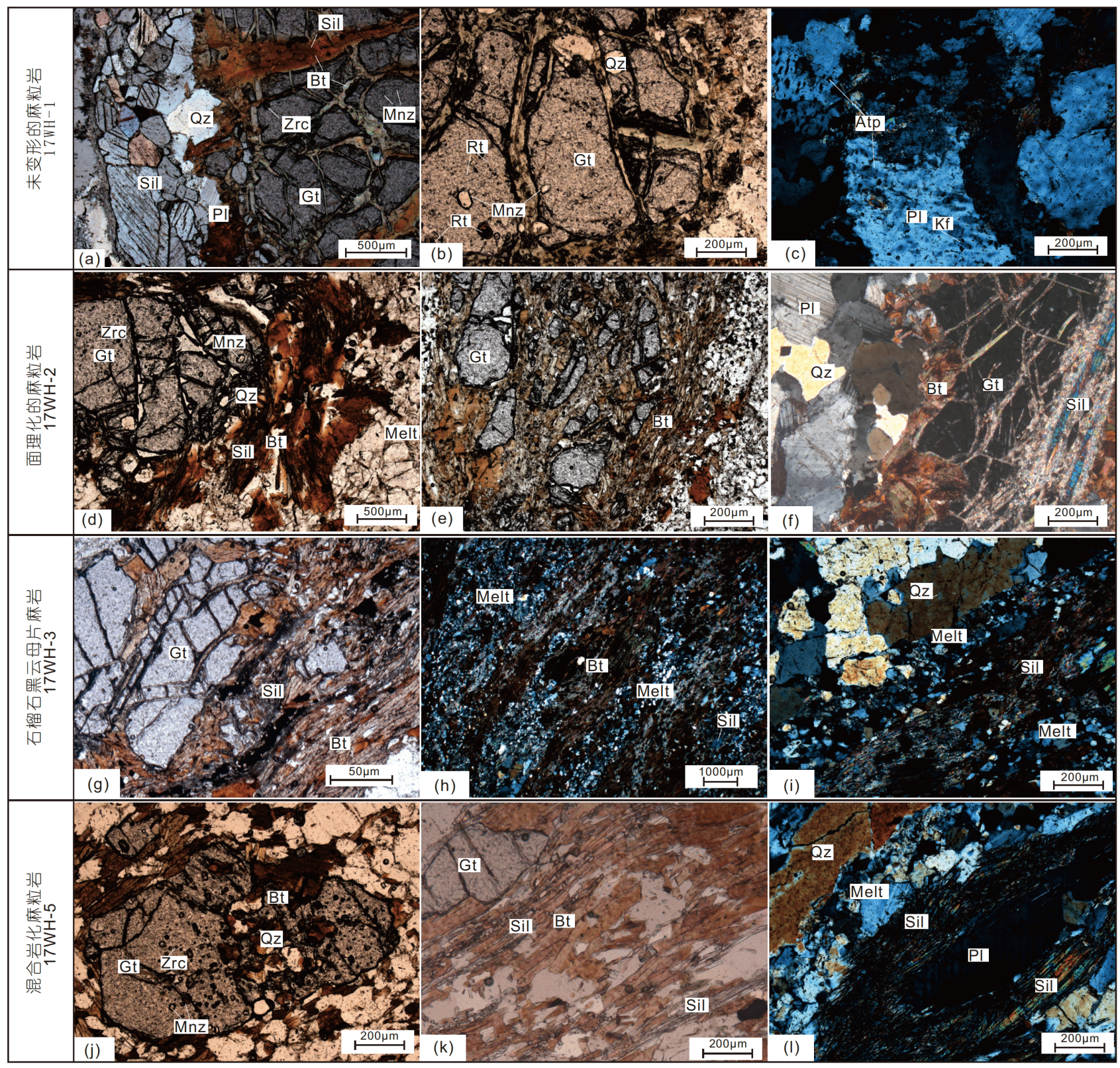

图 3 四类麻粒岩的显微照片

(a)、(b)、(j) 石榴石变斑晶中黑云母、石英、独居石和铅石包裹体及裂隙中的黑云母; (c) 反条纹长石: 斜长石中具有钾长石叶片晶出熔体; (d) 石榴石周围发育的黑云母和矽线石冠状体; (e) 石榴石残余体及呈弱定向的黑云母; (f) 呈定向的矽线石; (g)、(h)、(k)、(l) 基质中具有强烈 定向的黑云母和纤维状矽线石; (i)、(1) 基质中呈定向拉长的粗粒石英颗粒. 矿物代号: Gt, 石榴石; Bt, 黑云母; Qz, 石英; Pl, 斜长石; Atp, 反条 纹长石; Sil, 矽线石; Rt, 金红石; Kf, 钾长石; Zrc, 铅石; Mnz, 独居石; Melt, 熔体

中一些大颗粒的石英被显著拉长, 其定向性与黑云母 和矽线石相一致(图3i)。混合岩化麻粒岩(17WH-5，图 $2 \mathrm{e})$ 由暗色体和浅色体组成, 暗色体由黑云母 $(\sim 50 \%)$ 、
石榴石 $(\sim 5 \%)$ 、斜长石 $(\sim 20 \%)$ 、石英( 20\%)和矽线石 ( $5 \%)$ 组成, 浅色体则主要由石英、斜长石和钾长石组 成. 石榴石含量较少且粒度较小, 其中可见黑云母、石 
英、锆石和独居石包裹体(图3j). 在浅色体的基质中可 看到粗粒的石英和长石以及强烈定向的黑云母和矽线 石(图3k、31). 可见，四个岩石样品的镜下岩相学特征 和野外露头特征是一致的。

\section{3 分析方法}

利用碎样机对样品进行碎样, 分离出重矿物, 然后 在双目显微镜下从重矿物中挑选出独居石，置于环氧 树脂中，并将其抛光直至独居石内部结构暴露，制成 独居石靶. 本文对独居石的研究方法包括BSE成图、 原位U-Pb同位素定年和微量元素分析均在武汉上谱
分析科技有限责任公司进行，具体用到的实验仪器及 分析方法描述如下.

\section{1 独居石BSE成像}

采用分析扫描电子显微镜(JSM-IT100)对独居石 进行BSE图像的拍摄, 工作电压为10.0 20.0V, 铇灯丝 电流为70 80 $\mu \mathrm{A}$. 选取拍摄的具有代表性的BSE图像 如图4所示.

\section{2 独居石原位U-Pb定年及微量元素分析}

采用LA-ICP-MS对独居石进行U-Pb同位素分析 的同时完成微量元素分析. 仪器的激光剥蚀系统为

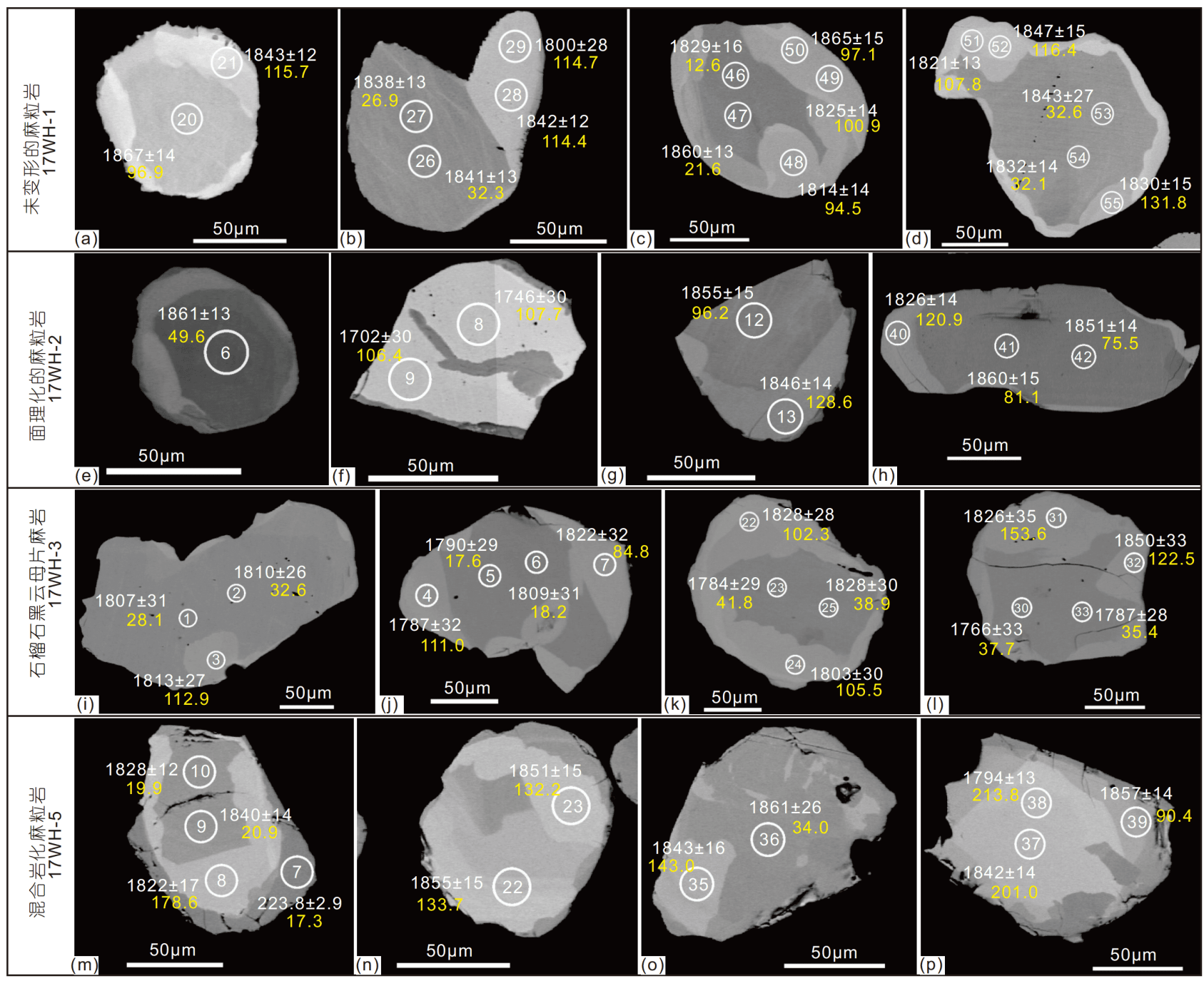

图 4 四类麻粒岩中独居石的代表性BSE图像

白色圈及其中数字代表分析位置及点号, 白色数字表示年龄结果 $(\mathrm{Ma})$, 黄色数字表示 $\mathrm{Th} / \mathrm{U}$ 值 
GeolasPro, 是由COMPexPro $102 \mathrm{ArF}$ 193nm准分子激 光器和MicroLas光学系统组成的, ICP-MS型号为Agilent $7700 \mathrm{e}$. 激光剥蚀过程中灵敏度的调节通过氦气 (载气)和氩气(补偿气) 实现, 这两种气体在经由一个 $\mathrm{T}$ 型接头进行混合之后再通入 ICP中, 激光剥蚀系统配 置有信号平滑装置, 采用该装置的优点是即便在激光 脉冲频率低至 $1 \mathrm{~Hz}$ 的情况下也可以获得平滑的分析信 号( $\mathrm{Hu}$ 等, 2015). 本次分析的激光束斑大小为 $16 \mu \mathrm{m}$, 频 率为 $2 \mathrm{~Hz}$. 每次分析均包括大约 $20 \sim 30 \mathrm{~s}$ 的空白信号采 集和 $50 \mathrm{~s}$ 的样品信号采集. 普通 $\mathrm{Pb}$ 的校正则基于 ${ }^{204} \mathrm{~Pb}$ 的测定. 分析的过程中采用标准物质44069作为外标 对独居石U-Pb同位素进行校正, 且每进行6次样品分 析继之2次的外标分析. TIM U-Pb定年给出独居石 44069 的年龄参考值为 $(424.9 \pm 0.4) \mathrm{Ma}$ (Aleinikoff等, 2006). 整个分析过程共对44069标样进行了 90 次分析, 获得其 ${ }^{206} \mathrm{~Pb} /{ }^{208} \mathrm{U}$ 加权平均年龄为 $(424.7 \pm 0.9) \mathrm{Ma}$ $(\mathrm{MSWD}=0.28)$. 在进行 $\mathrm{U}-\mathrm{Pb}$ 定年的同时也进行了独居 石微量元素分析. 采用外标NIST 610 对测定的微量元 素进行校正, 此外采用Ce作为内标元素对独居石微量 元素进行归一化处理(Buick等, 2010). 上述的数据处 理所用到的软件包括ICPMSDataCal(Liu等, 2010)和 Isoplot/Ex_ver3(Ludwig, 2003). 独居石同位素比值和 微量元素含量数据分别见网络版附表 1 和 2 (http:// earthen.scichina.com).

\section{4 分析结果}

\section{1 独居石形貌学}

威海泥质麻粒岩中的独居石以包裹体形式存于石 榴石之中(图3a、3d、3j), 或是存在于基质中, 在BSE 图像中可以观察到这些独居石多具有明显的分带结构 (图4). 未变形的麻粒岩(17WH-1)中的独居石呈次圆状 到棱角状, 颗粒大小 $50 \sim 200 \mu \mathrm{m}$ 不等. BSE图像显示其 中大部分独居石颗粒具有简单的分带结构, 即暗灰色 的核部以及外缘较亮的边部(图4a 4d). 面理化的麻粒 岩(17WH-2)中的独居石为次等轴状或是长轴状, 大小 在50 150 $\mu \mathrm{m}$ 之间(多为 $100 \mu \mathrm{m}$ 左右), 其中大部分颗粒 也具有核边结构: 暗灰的核和亮的边(图 $4 \mathrm{e} 、 4 \mathrm{~g} 、 4 \mathrm{~h}$ ). 只有少量独居石具有较为明亮的区域较大的部分, 并 且被窄的暗灰色的边所围绕, 其中一个独居石还保留 着残留的暗灰色的核(图4f). 石榴石黑云母片麻岩
(17WH-3)中的独居石与面理化的麻粒岩(17WH-2)中 的具有类似的结构特征(图4i 41). 混合岩化麻粒岩 (17 W H-5) 中的独居石为椭圆或块状, 粒度也在 $50 \sim 150 \mu \mathrm{m}$ 之间. 该样品中的独居石按其分带特征可以 分为两组: 一组独居石颗粒可识别出两个分带域, 即暗 灰色的部分和亮的部分, 且暗灰色的部分多被亮的部 分所截穿(图4o、4p); 另一组独居石颗粒则具有三个 分带域, 由暗灰色的核、亮的幔部及窄的暗灰色边部 组成(图 $4 m 、 4 n 、 4 p)$, 不过这些暗灰色增生边窄于激 光剥蚀束斑大小而难以被分析(图 $4 n 、 4 p)$. 总的来看, 上述四类样品中的独居石具有核边(亮的边)或者是核 幔边(暗灰色的边)的分带结构. 此外值得注意的是, 这 些具有分带结构独居石的核部和边部的界限普遍呈尖 锐状(图4c、4d、4j 4n、4p).

\section{2 独居石 $\mathrm{U}-\mathrm{Pb}$ 年代学及微量元素特征}

\subsection{1 未变形的麻粒岩(17WH-1)}

对该样品中 23 颗独居石63个点进行了LA-ICP-MS 分析, 其中核部有 31 个分析点, 边部则有 32 个分析点. 独居石U-Th-Pb同位素结果见网络版附表1, 微量元素 分析结果见网络版附表2. 独居石不同区域的 Th和U含 量不同. 暗的核部具有高的U含量(613 4379ppm, $1 \mathrm{ppm}=1 \mu \mathrm{g} / \mathrm{g})$ 、低的 $\mathrm{Pb}$ 含量(5073 20046ppm) 和 $\mathrm{Th}$ 含 量(50504 241056ppm), Th/U比值较低(12.6 208.7, 多 低于100)(图5a). 相反, 独居石的边部则具有高的 $\mathrm{Pb}$ 含 量(9952 21485ppm)和Th含量(121703 264670ppm), 但U含量较低(684 2274ppm), Th/U比值则比较高 (94.5 223.2, 多高于100)(图5a). 可见, 具有分带结构 独居石的不同的区域的 $\mathrm{Th} / \mathrm{U}$ 比值是不同的，可视为一 个区分独居石不同域的指标(图4a 4d). 所有的分析点 给出上交点年龄为 $(1836 \pm 11) \mathrm{Ma}(\mathrm{MSWD}=1.8)$. 分析点 给出的年龄值具有较高的谐和度, 其中 40 个点给出谐 和 ${ }^{206} \mathrm{~Pb} /{ }^{208} \mathrm{U}$ 年龄范围为 $(1782 \pm 14) \sim(1871 \pm 16) \mathrm{Ma}$, 加权 平均值为 $(1832 \pm 7) \mathrm{Ma}(\mathrm{MSWD}=2.2)$, 另外, 位于核部和 边部的谐和年龄给出加权平均值分别为 $(1832 \pm 10) \mathrm{Ma}$ $(M S W D=2.4)$ 和 $(1822 \pm 11) \mathrm{Ma} \quad(M S W D=3.0)$ (网络版附 表1; 图6a). 因此, 尽管独居石具有分带结构, 而且不 同域的元素含量也有变化, 但独居石核部和边部具有 一致的 ${ }^{206} \mathrm{~Pb} /{ }^{208} \mathrm{U}$ 年龄. 独居石的稀土模式图呈明显的 右倾，具有强烈的LREE富集、HREE亏损和明显的 $\mathrm{Eu}$ 负异常(图7a). 具体来看, 相比于边部, 独居石核部具 

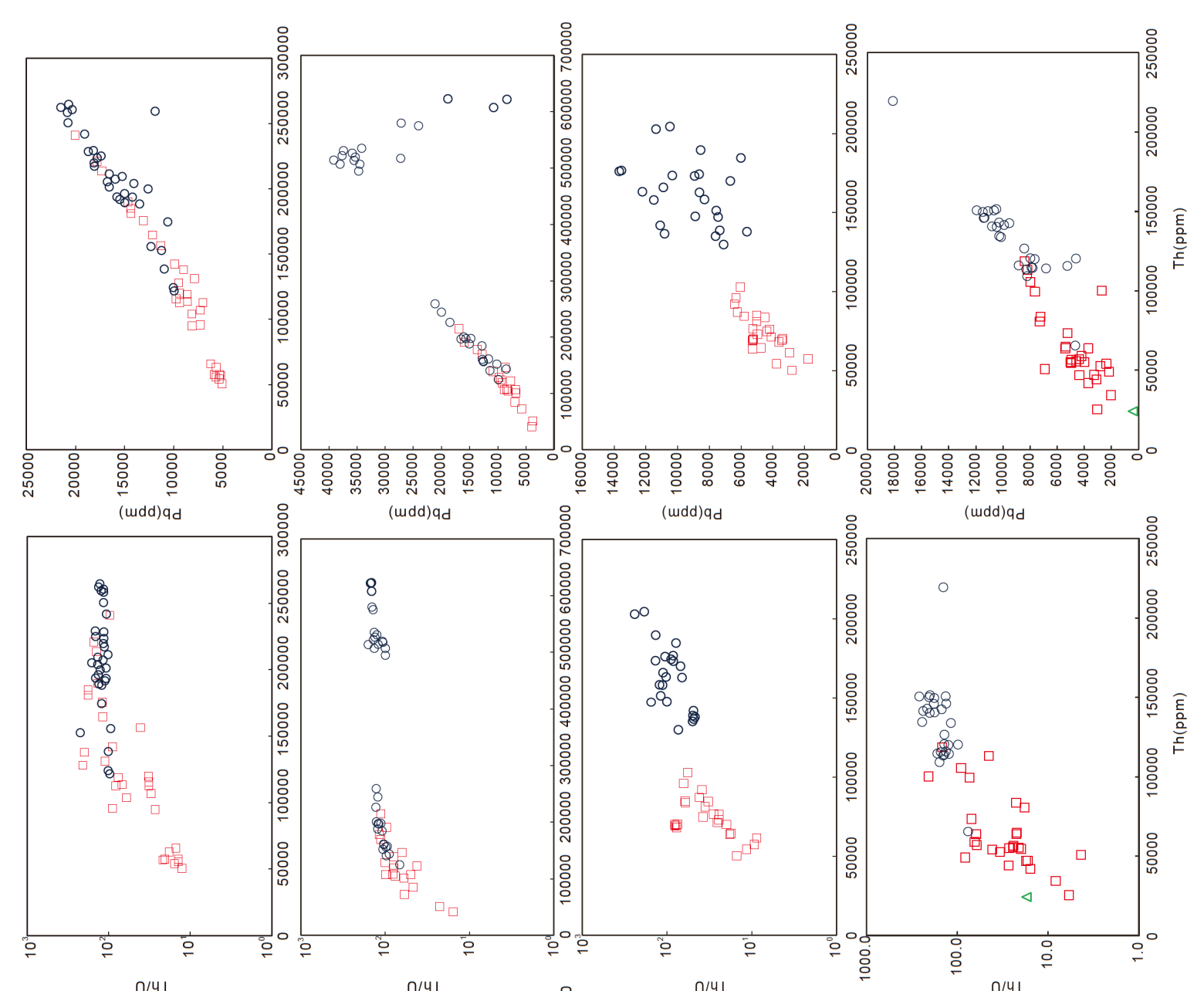

进朕
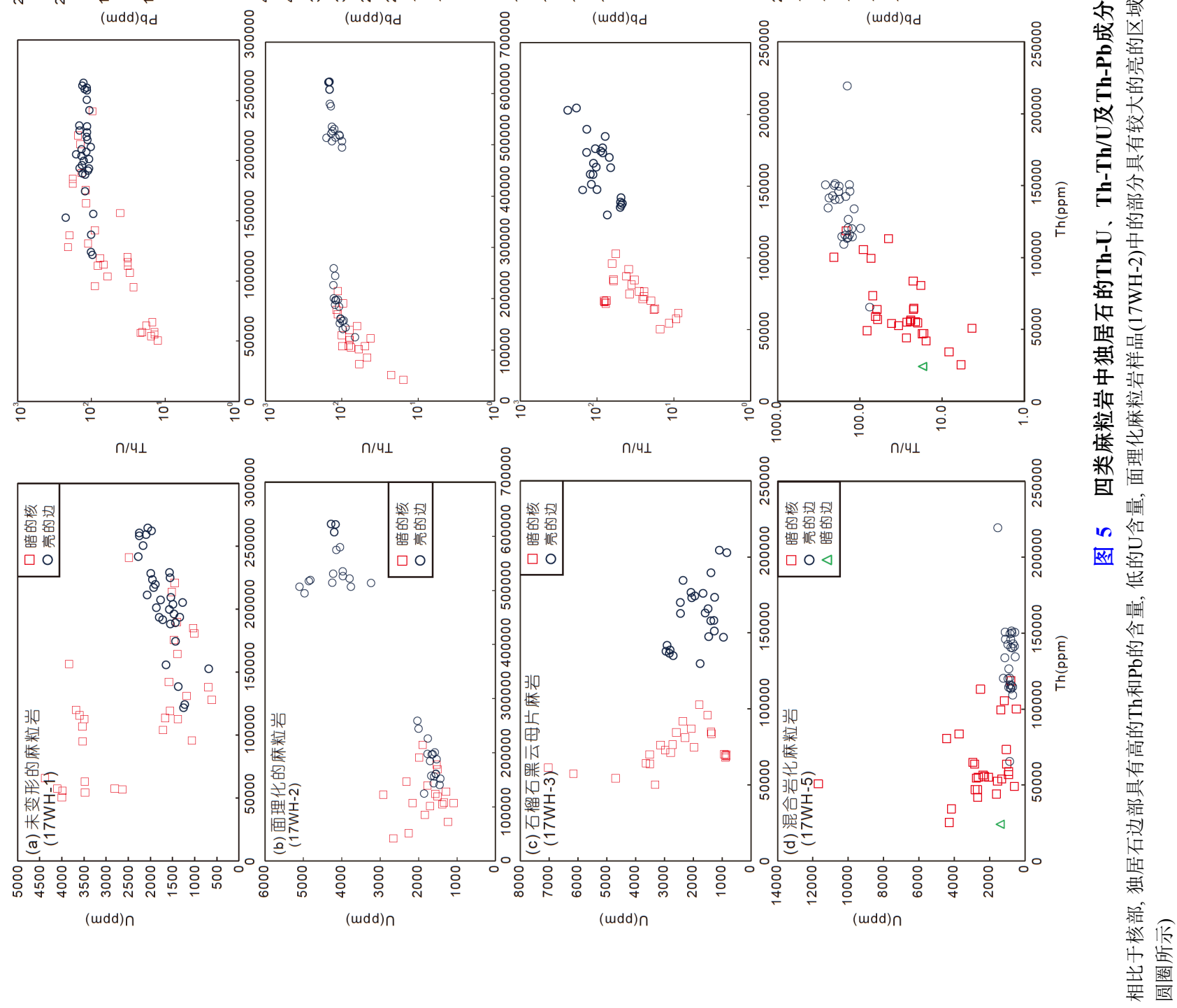

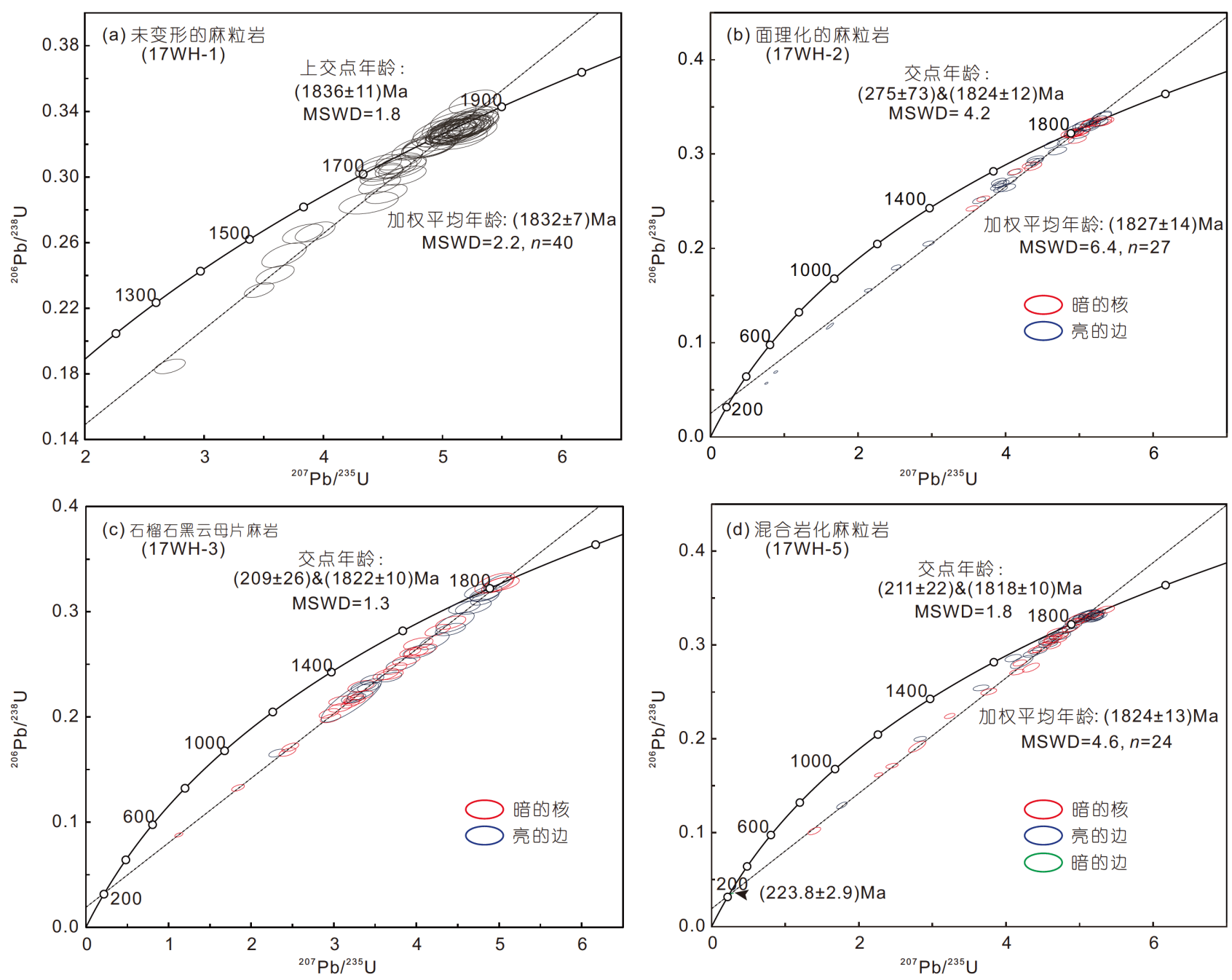

图 6 四类麻粒岩中的独居石U-Pb年龄谐和图

有更高的 $\mathrm{Eu} / \mathrm{Eu}^{*}$ 值(0.04 0.08)、HREE含量(2096 $8377 \mathrm{ppm}$ )和Y含量(121 2103ppm)(图8a).

\subsection{2 面理化的麻粒岩(17WH-2)}

对该样品中 20 个独居石颗粒的 52 个点进行 LAICP-MS定年和微量元素分析, 相应的数据分别见网络 版附表1和2. 独居石核部的19个分析点显示其具有低 的 $\mathrm{Th}$ 含量 (4 $1520 \sim 214608 \mathrm{p} \mathrm{p} \mathrm{m}$ ) 和 $\mathrm{Pb}$ 含量 (3768 16921ppm), 高的U含量(1090 2923ppm), Th/U 比值较低(15.6 116.4, 多低于100)(图5b). 而边部的17 个分析点则显示出具有高的 $\mathrm{Pb}$ 含量(9899 21152ppm) 和 $\mathrm{Th}$ 含量 $(124830 \sim 259206 \mathrm{ppm})$, 但 U含量低 (1859 2031ppm), 致使高的 Th/U比值(67.1 128.6)(图
$5 b$ ). 其余16个分析点位于独居石较大且亮的区域(图 4f), 结果显示其具有非常高的 $\mathrm{Pb}(8370 \sim 39159 \mathrm{ppm})$ 、 $\mathrm{Th}(494676 \sim 622753 \mathrm{ppm})$ 和U(3240 5107ppm)的含量, $\mathrm{Th} / \mathrm{U}$ 比值也比较高(99.3 158.5)(图5b中右上角圆圈所 示). 在年龄谐和图中，这16个分析点的同位素结果均 落在不一致线上, 表明该部分受到了显著的 $\mathrm{Pb}$ 丢失(图 $6 b)$. 然而, 独居石的核部和边部的 ${ }^{206} \mathrm{~Pb} /{ }^{208} \mathrm{U}$ 年龄并没 有不同(网络版附表1). 所有的分析点给出交点年龄为 $(275 \pm 73) \mathrm{Ma}$ 及 $(1824 \pm 12) \mathrm{Ma}(\mathrm{MSWD}=4.2)$, 位于核部和 边部的谐和 ${ }^{206} \mathrm{~Pb} /{ }^{208} \mathrm{U}$ 年龄的加权平均值分别为 $(1828$ $\pm 17) \mathrm{Ma} \quad(\mathrm{MSWD}=4.2, n=13)$ 和 $(1841 \pm 18) \mathrm{Ma}$ $(\mathrm{MSWD}=3.8, n=12)$ (网络版附表1; 图6b). 独居石的核 部和边部均表现出LREE富集、HREE强烈亏损和明 

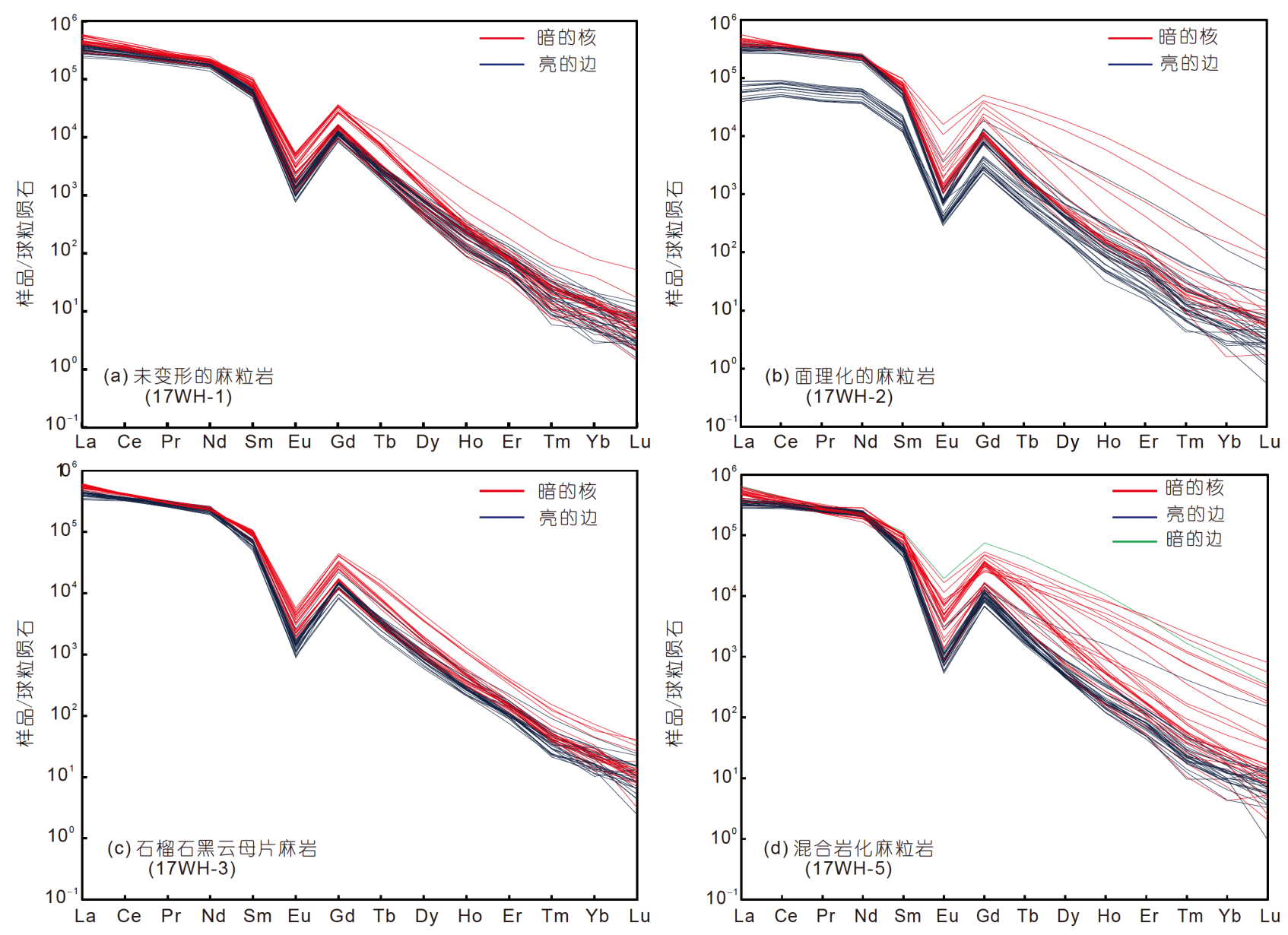

图 7 四类麻粒岩中的独居石球粒陨石均一化稀土元素配分模式图

标准化值据Sun和McDonough(1989)

显的 $\mathrm{Eu}$ 负异常(图7b). 具体来说, 独居石的核部具有高 的 $\mathrm{Eu} / \mathrm{Eu}^{*}$ 值(0.02 0.22)、HREE含量(1598 17758ppm) 和Y含量(112 12061 ppm), 而边部则具有低的 $\mathrm{Eu} / \mathrm{Eu}^{*}$ 值 (0.02 0.1), 更加亏损HREE(537 5392ppm) 和Y (62 2515ppm)(图8b).

\subsection{3 石榴石黑云母片麻岩(17WH-3)}

对该样品中的 12 个独居石颗粒的 59 个点进行了 LA-ICP-MS分析, 其中核部有 22 个点, 边部有 24 个分析 点, U-Th-Pb同位素及微量s元素结果分别见网络版附 表1和2. 独居石的核部具有低的 $\mathrm{Pb}$ 含量(1773 $6413 \mathrm{ppm})$ 和Th含量(50128 102817ppm), 但U含量比较 高(859 7031ppm), Th/U比值较低(8.7 81.3)(图5c); 而 独居石的边部具有高的 $\mathrm{Pb}$ 含量(5634 13665ppm)和 $\mathrm{Th}$
含量 (129722 204376p pm), U含量则比较低 (842 2947ppm), 导致Th/U比值较高(46.8 240.7)(图 $5 \mathrm{c})$. 由于 $\mathrm{Pb}$ 的丢失, 这些分析点均落在不一致线上, 给出交点年龄为 $(209 \pm 26) \mathrm{Ma}$ 和 $(1822 \pm 10) \mathrm{Ma}$ $(\mathrm{MSWD}=1.3)$ (图6c). 独居石核部和边部均表现出强烈 富集LREE、亏损HREE和Eu负异常(图7c). 同样, 独居 石核部的 $\mathrm{Eu} / \mathrm{Eu}^{*}$ 值 $(0.04 \sim 0.08)$ 、 HREE含量 (2750 11024ppm) 和Y含量(405 1857ppm)更高, 而边 部则具有低的 $\mathrm{Eu} / \mathrm{Eu}^{*}$ 值 $(0.02 \sim 0.06) 、 \mathrm{HREE}$ 含量 (1923 5290ppm)和Y含量(254 742ppm)(图8c).

\subsection{4 混合岩化麻粒岩(17WH-5)}

该样品中 20 颗独居石共 56 个LA-ICP-MS分析点获 得的U-Th-Pb同位素及微量元素数据分别见网络版附 


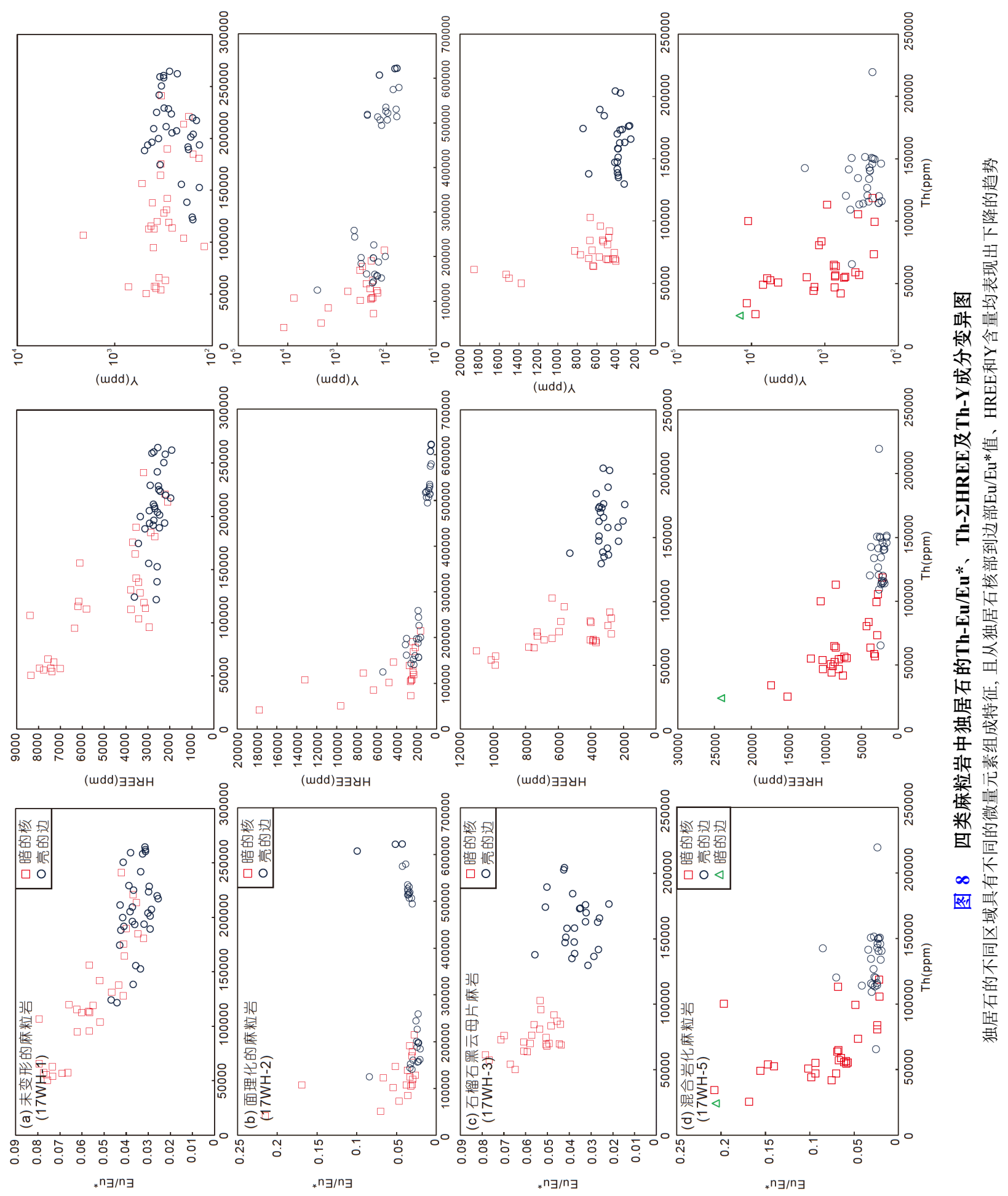


表1和2. 独居石核部 28 个分析点显示其具有低的 $\mathrm{Pb}$ 含 量(2042 8413ppm)和Th含量(25333 118591ppm), 高 的 $U$ 含量 $(484 \sim 11691 \mathrm{ppm})$, 以及低的 $\mathrm{Th} / \mathrm{U}$ 比值 (4.3 206.7, 多低于100)(图5d). 相比于核部, 独居石边 部 (幔部) 的 27 个分析点显示其具有高的 $\mathrm{Pb}$ (4623 18126ppm)和 Th(65528 219450ppm)含量, U含 量较低(552 1542ppm), Th/U值较高(75.8 262)(图5d). 所有分析点给出交点年龄为 $(211 \pm 22) \mathrm{Ma}$ 及 $(1818 \pm 10)$ $\mathrm{Ma}(\mathrm{MSWD}=1.8) .25$ 个 ${ }^{206} \mathrm{~Pb} /{ }^{208} \mathrm{U}$ 谐和年龄范围为 $(1758$ $\pm 16) \sim(1874 \pm 14) \mathrm{Ma}$ ，其中核部11个谐和年龄给出加权 平均值为 $(1825 \pm 24) \mathrm{Ma}(\mathrm{MSWD}=5.5)$, 边部14个谐和 年龄的加全平均值为 $(1830 \pm 14) \mathrm{Ma}(\mathrm{MSWD}=2.8)$ (网络 版附表1; 图6d). U-Pb同位素结果表明独居石核部和边 部具有相同的年龄. 其中一个独居石具有暗灰色的边 部, 记录有三叠纪的年龄 $(223.8 \pm 2.9) \mathrm{Ma}$ (图4m、6d), 相比于独居石的其他区域，该暗灰色的边部具有最低 $\mathrm{Pb}$ 含量(436ppm)及 $\mathrm{Th}$ 的含量(24174ppm)(图5d). 样品 中独居石的稀土模式配分图显示其强烈富集LREE、 亏损HREE及具有 $\mathrm{Eu}$ 负异常(图7d). 从独居石的核部到 边部, $\mathrm{Eu} / \mathrm{Eu}^{*}$ 的值、 HREE和Y的含量显示出降低的趋 势，从0.02 0.21、2148 17298ppm和210 11639ppm到 $0.02 \sim 0.09 、 1587 \sim 3865 \mathrm{ppm}$ 和169 1878ppm(图8d). 相 比于其他区域，记录三叠纪年龄的边部具有高的 $\mathrm{Eu} /$ $\mathrm{Eu}^{*}$ 值 (0.21), 最高的HREE含量 $(24101 \mathrm{ppm})$ 和 $\mathrm{Y}$ 含量(14502ppm)(图7d、8d).

\section{3 独居石 $\mathrm{Si}$ 和P元素组成特征}

具有分带结构且伴随有化学成分变化特征的独居 石多发现于麻粒岩相变质岩中(Zhu和O'Nions，1999a; Kelly等, 2012; Taylor等, 2014; Xu等, 2019). 越来越多 的研究认为此种独居石的成因应和流体改造作用之下 发生的离子替代反应相关 $\left(\mathrm{Th}^{4+}+\mathrm{Si}^{4+}=(\mathrm{Y}+\mathrm{REE})^{3+}+\mathrm{P}^{5+}\right)$ (Poitrasson等, 1996; Zhu和O'Nions, 1999a; Williams等, 2007; Harlov等, 2011; Kelly等, 2012). 因此, 有必要分 析 $\mathrm{Si}$ 和P从独居石核部到边部的变化特征. 如图9所示, 独居石亮的边部具有比其核部更高的 $\mathrm{Si}$ 含量, 但是也 有部分分析值是重合的. 特别是在面理化的麻粒岩 (17WH-2)样品中, 独居石的边部尤其是较大且明亮的 部分(图4f)具有比核部更为显著的高的 $\mathrm{Si}$ 含量, 高至 $82918 \mathrm{ppm}$ (图9b). 与 $\mathrm{Si}$ 元素含量的变化趋势相反, 独居 石的边部比核部具有明显的低的 P含量. 上述面理化的
麻粒岩样品中独居石BSE图所显示明亮的部分表现出 非常低的P的含量, 低至17483ppm(图9b). 总体来看, 从 独居石的核部到其边部, P 的含量和Th的含量具有负 相关关系(图9).

\section{5 讨论}

\section{1 古元古代麻粒岩相独居石}

麻粒岩相变质作用以出现高温变质矿物组合为特 征(O’Brien, 2000; 翟明国和刘文军, 2001; Brown和 Johnson, 2019). 在苏鲁造山带海阳所及威海地区存在 古元古代 $(\sim 1.8 \mathrm{Ga})$ 麻粒岩相变质作用的记录. 在海阳 所地区, 古元古代麻粒岩相片麻岩具有石英+黑云母 +石榴石 + 斜长石 + 金红石的峰期矿物组合 (Liou等, 2006; Liu等, 2017; Feng等, 2020). 在威海地区也报道 了具有古元古代 $(1.84 \mathrm{Ga})$ 变质年龄的高温-超高温泥 质麻粒岩(Xiang等, 2014; Lei等, 2014; Xu等, 2019; 熊 志武等, 2021). 威海泥质麻粒岩的峰期矿物组合为石 榴石 + 矽线石 $+反$ 条纹长石 + 斜长石 + 石英 + 金红石土黑 云母, 并通过相平衡(Xiang等, 2014)及锆石 Ti含量温度 计(Xu等，2019)方法限定了其超高温麻粒岩相变质作 用条件 $\left(>900^{\circ} \mathrm{C}, 11 \sim 13 \mathrm{kbar}\right)$.

本文研究的泥质麻粒岩透镜体, 从核部到边部出 现四类不同的岩性，依次为: 未变形的麻粒岩、面理 化的麻粒岩、石榴石黑云母片麻岩和混合岩化麻粒岩 (图2). 它们具有相同的麻粒岩相峰期矿物组合, 包括 石榴石 + 斜长石(反条纹长石)+石英+矽线石 + 黑云母及 副矿物金红石、锆石和独居石(图3). 上述四类样品中 的独居石均具有暗灰色的核部、亮的边部(幔部), 有 或无窄的暗灰色边的分带结构(图4). 具有此种特征的 独居石常见于麻粒岩相岩石中(Zhu和O'Nions，1999a; Kelly等, 2012; Bhowmik等, 2014; Taylor等, 2014; Wu 等, 2014; Xu等, 2019). 此外, 这些独居石的稀土元素配 分模式图显示其具有强烈亏损HREE和Y以及明显的 $\mathrm{Eu}$ 负异常(图7、8). 石榴石是富集HREE和Y元素的变 质矿物, 而 $\mathrm{Eu}$ 则会在优先进入长石之中(Foster等, 2002; Hermann和Rubatto，2003; Rubatto等，2006; Buick等, 2010), 因此当独居石和这两种变质矿物同期 生长时, 将会出现上述的独居石HREE和Y亏损、Eu负 异常的特征. 而威海地区的泥质麻粒岩(Xiang等, 2014; Xu等，2019)以及本文研究的样品(图3)中是含有石榴 

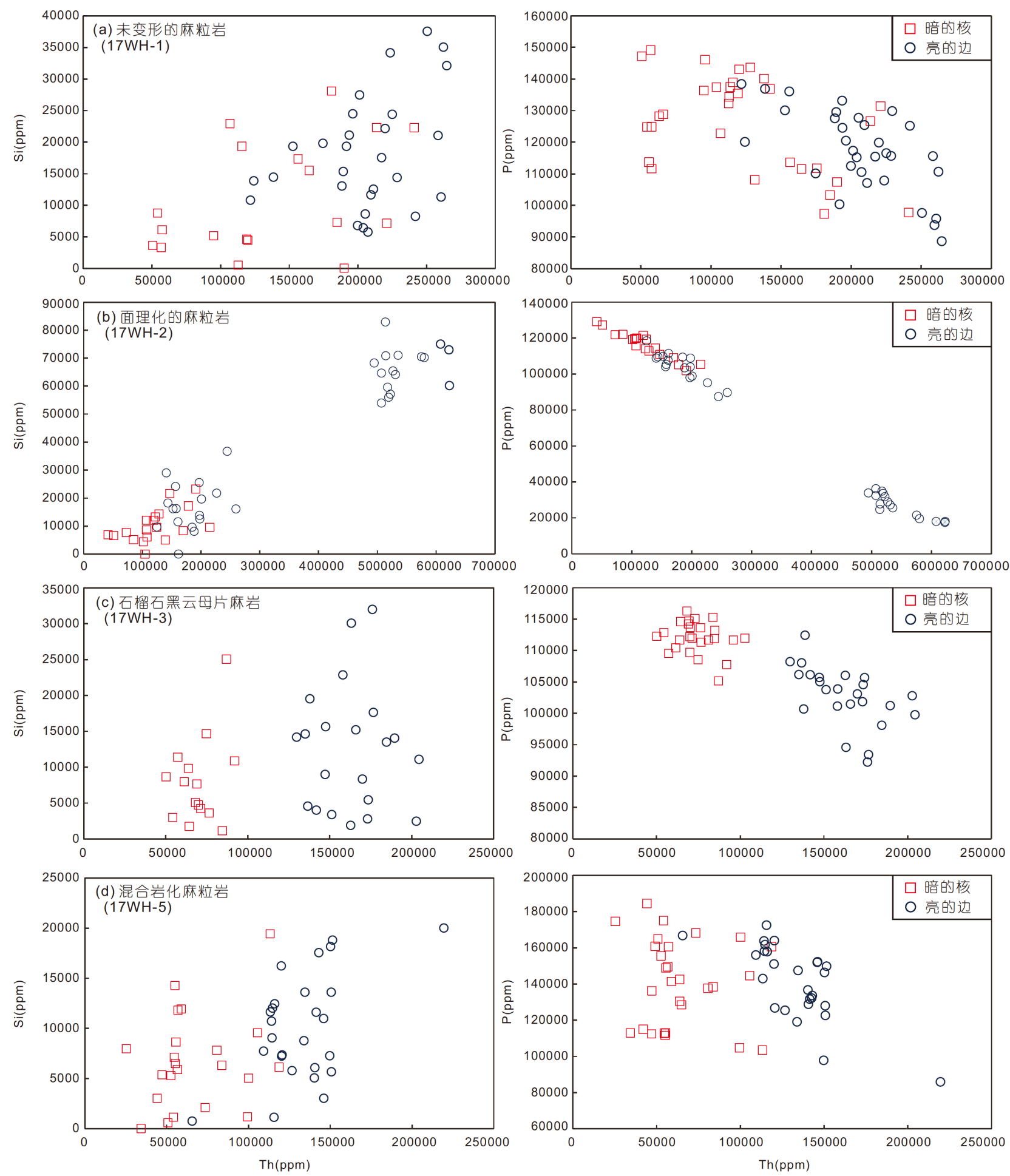

图 9 四类麻粒岩中独居石的 Th-Si和Th-P成分变异图

独居石核部和边部具有不同的元素含量特征, 从核部到边部, Si含量增加, 而P的含量降低 


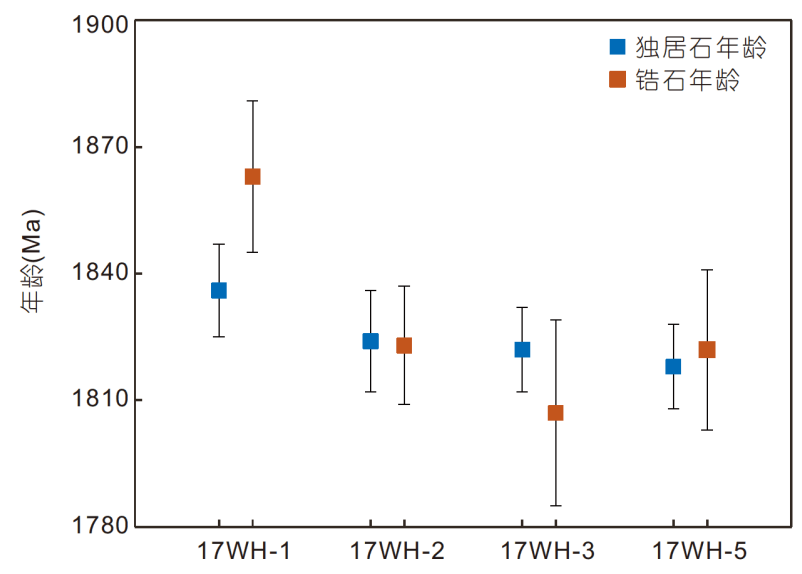

图 10 四个样品中的独居石与锆石所记录年龄对比图

独居石记录了和锆石误差内相一致的 U-Pb年龄, 锆石 $\mathrm{U}-\mathrm{Pb}$ 年龄数据 引自熊志武等(2021)

石和长石这两种峰期变质矿物的. 因此可推测古元古 代独居石生长于麻粒岩相变质作用过程.

根据BSE图，对麻粒岩相独居石不同区域进行了 LA-ICP-MS定年. 四类麻粒岩中 (样品 $17 \mathrm{WH}-1$ 、 $17 \mathrm{WH}-2 、 17 \mathrm{WH}-3$ 和 $17 \mathrm{WH}-5)$ 的独居石给出上交 点 ${ }^{206} \mathrm{~Pb} /{ }^{208} \mathrm{U}$ 年龄分别为 $(1836 \pm 11) 、(1824 \pm 12) 、(1822$ $\pm 10)$ 及 $(1818 \pm 10) \mathrm{Ma}$ (图6). 年龄结果表明四类麻粒岩 具有误差范围内相一致的古元古代年龄, 代表了麻粒 岩相变质作用的时代.

锆石是高级变质岩中另一种非常重要的副矿物, 因其富集U和 $T h, U-T h-P b$ 同位素体系封闭温度高而被 视为一种可靠的定年工具(Cherniak和Watson, 2001; Wu和Zheng, 2004). 通常情况下同一个高级变质岩中 的独居石 $\mathrm{U}-\mathrm{Pb}$ 年龄趋向于晚于变质锆石年龄 (Harley 和Nandakumar, 2014; $\mathrm{Wu}$ 等, 2014). 大量研究表明, 独 居石也可以记录与锆石相一致的年龄信息(Rubatto等, 2001; Taylor等, 2014; Xu等, 2019). 在之前的研究中(熊 志武等, 2021), 变质锆石给出的古元古代U-Pb年龄和 本研究中独居石记录的年龄在误差范围内相一致(图 10). 也就是说, 独居石古元古代的年龄和前人报道过 的苏鲁造山带内泥质麻粒岩锆石记录的 $\mathrm{U}-\mathrm{Pb}$ 年龄结 果一致(Xiang等, 2014; Xu等, 2019; 熊志武等, 2021).

\section{2 三叠纪流体改造独居石}

威海古元古代泥质麻粒岩是否经历了三叠纪大陆 碰撞过程中变质作用的叠加, 目前仍处于争论之中
(Xiang等, 2014; Xu等, 2019). 这些泥质岩中的锆石并 没有体现出这方面的信息(Xiang等, 2014; Xu等, 2019; 熊志武等, 2021). 然而, 本研究中的独居石则清晰地表 明了古元古代的独居石受到了三叠纪大陆碰撞过程中 流体的改造.

BSE图像揭示了本文中独居石所具有的普遍特征 是核-(有或无幔部)-边分带结构(图4), 亮的边呈港湾 状, 暗灰色的核则具叶状或尖锐状. 独居石的化学成 分同样也有变化. 独居石核部具有低的 $\mathrm{Pb}$ 和 $\mathrm{Th}$ 含量, $\mathrm{U}$ 含量较高, $\mathrm{Th} / \mathrm{U}$ 比值低; 而独居石边部则具有高的 $\mathrm{Pb}$ 和 $\mathrm{Th}$ 含量、低的 $\mathrm{U}$ 含量, $\mathrm{Th} / \mathrm{U}$ 比值较高(图5、11). 此外, 独居石的边部比核部更加亏损HREE和Y(图8). 对于 $\mathrm{Si}$ 和P这两种元素, 边部具有比核部高的 $\mathrm{Si}$ 含量, 低的P含量(图9). 首先要注意的是, 这些元素的变化机 制应与体积扩散过程无关, 因为在地质时间尺度上, 即 使在相对较高的温度下, 这些元素在独居石中的扩散 速率也是非常低的(Cherniak等, 2004; Gardés等, 2006; McFarlane和Harrison, 2006; Cherniak和Pyle, 2008). 因 此需要一个可靠的机制来解释具有分带结构独居石的 成因.

变质岩中独居石具有的分带结构和伴随的化学成 分变化特征已经被广泛报道(Zhu和O'Nions, 1999a; Kelly等, 2012; Bhowmik等, 2014; Taylor等, 2014; Xu 等, 2019). 总体来说, 对具分带结构独居石成因的主要 观点包括早期碎屑独居石的部分溶解及再生长( Lasalle等, 2014)、独居石的幕式生长(Bhowmik等, 2014; Mottram等, 2014; Xu等, 2019) 以及流体对原有独居石 的改造(Zhu和O'Nions, 1999a; Ayers等, 2002; Kelly等, 2012; Taylor等, 2014).

早期碎屑独居石的部分溶解和再生长是导致独居 石分带的原因之一. 但本文中独居石的分带结构成因 应与部分溶解和再生长机制无关, 理由如下: (1) 如上 文所述，同一个独居石颗粒或者同一个样品中的不同 独居石颗粒不同区域的REE特征是相似的(图7), 然而 对于碎屑独居石来说，其REE模式将会有很大的不同 (Zhu和O'Nions, 1999b; Rasmussen和Muhling, 2007, 2009; Wang等, 2017); (2) 从年代学角度来说, 如果变 质岩中存在碎屑成因独居石, 其将会具有比新生独居 石老得多的年龄(Rasmussen等, 2007; Lasalle等, 2014; Wang等, 2017), 但本文古元古代的独居石, 无论是核 部还是边部, 记录的年龄是一致的. 


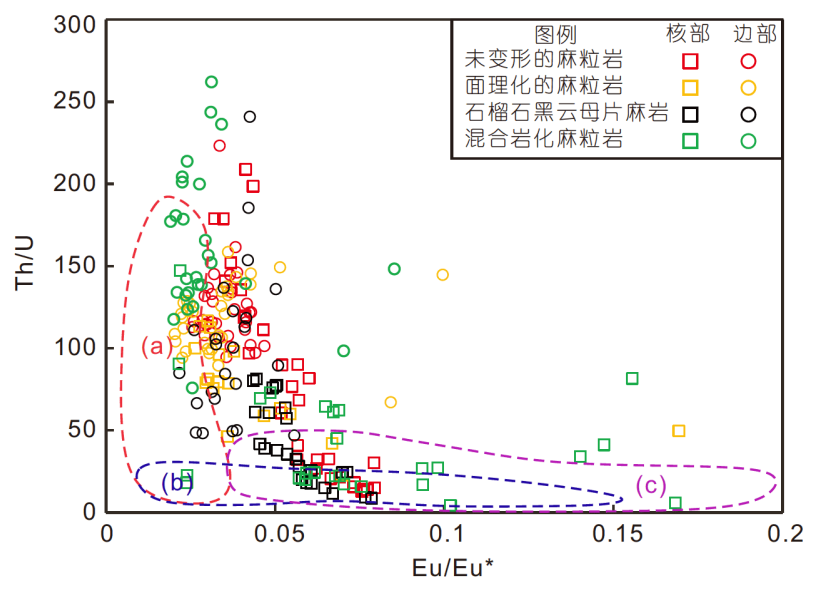

图 11 本文及其他麻粒岩相变质岩中独居石的 $\mathrm{Eu} / \mathbf{E u}{ }^{*}-\mathrm{Th} /$ U图

(a) 南印度Trivandrum地体麻粒岩相变质岩中的分带独居石(Taylor 等, 2014); (b) 南印度Nagercoil地体麻粒岩相混合岩中的分带独居 石(Johnson等，2015); (c) 桐柏造山带麻粒岩中的无分带的独居石 (Wu等, 2014)

独居石的幕式生长是形成分带结构的另一种可能 机制. 大量的研究已表明这种成因的独居石的HREE 和Y元素分带可以用来限定变质作用过程的时代和持 续时间(Foster等，2002；Gibson等，2004; Mottram等， 2014; Wang等, 2017)，这些元素的亏损或者富集与石 榴石参与的变质反应有关，而且对应于年龄的分带. Johnson等(2015)报道了南印度Nagercoil地块中出露的 超高温麻粒岩相混合岩中的分带结构独居石，其BSE 显示明亮的部分具有亏损REE和高的 Th/U比值的特 征，不过其化学元素分带对应着年龄的变化，而且其 $\mathrm{Th} / \mathrm{U}$ 值(8 19)远低于本文的值(图 11). Bhowmik等 (2014)报道了中印构造带麻粒岩地体中的具分带结构 的独居石, 由于生长机制不同, 独居石颗粒保留有多期 次的生长分带, 因而记录了不同的表面年龄, 认为独居 石外缘高 $\mathrm{Th}\left(\mathrm{ThO}_{2}=14.1 \sim 22.1 \mathrm{wt} \%\right)$ 的边是由黑云母脱 水熔融产生的高温深熔熔体结晶而成. Xu等(2019)也 报道了威海泥质麻粒岩中具有高 $T h$ 含量边的独居石, 认为分带的独居石是从超高温 $\left((928 \pm 10)^{\circ} \mathrm{C}\right)$ 深熔熔体 中结晶而来的，而高 $\mathrm{Th}$ 则是因为 $\mathrm{Th}$ 比U更易进入结晶 的独居石. 同样，这些独居石从核部到边部记录的年 龄是逐渐年轻的，而本文研究的样品中独居石核边记 录的年龄并没有明显不同(图6). 因此，即便独居石是 在一个很短的时间内生长，幕式生长这一机制也无法 解释本文独居石分带结构成因, 特别是 $\mathrm{Th}$ 、 $\mathrm{Si}$ 、
HREE、Y和P这些元素的含量变化.

由于独居石广泛分布于麻粒岩相变质岩或熔体 中, 因此一般认为其具有较强的抗热扰动的能力 $(\mathrm{Wu}$ 等, 2014, 以及其中引用的文献). 然而当流体存在时, 甚至在低温的条件下，独居石可以部分或者是全部的 被流体改造(Ayers等，2002; Seydoux-Guillaume等， 2012). 如上文中所讨论, 独居石边部之于核部在 $T h$ 和 Si含量上的升高, REE、Y及 $\mathrm{P}$ 含量上的降低(图5、 7 9)是不能够通过元素扩散、碎屑独居石部分溶解之 后再生长和独居石幕式生长来解释的. Zhu和O'Nions (1999a)将具有上述元素变化特征的带状独居石成因 与流体作用相联系, 并指出成分的变化应是离子替代 反应的结果: $\mathrm{Th}^{4+}+\mathrm{Si}^{4+}=(\mathrm{Y}+\mathrm{REE})^{3+}+\mathrm{P}^{5+}$ (Förster, 1998; Williams等, 2007). Kelly等(2012)对东Antarcitica Oygarden群岛中的Mg-Al麻粒岩中具有分带结构的独居 石进行了详细的研究, 独居石的边部具有高的 $T h$ 含量 $\left(\leq 22 \mathrm{wt} \% \mathrm{ThO}_{2}\right)$ 及 $\mathrm{Si}$ 含量, 但亏损HREE、 $\mathrm{Y}$ 和 $\mathrm{P}$, 认为 高 Th部分形成于流体作用下的以溶解-再沉淀过程主 导的重结晶过程. Taylor等(2014)报道过南印度Trivandrum地块石榴石黑云母片麻岩和石榴角闪岩中边部 具有高 $\mathrm{Th}$ 和 $\mathrm{Si}$ 特征的独居石, 也认为独居石的边部形 成于碱性流体作用下的原有颗粒的改造过程(图 11). 这些元素在天然样品独居石中得到重新分配的机制也 被许多的实验研究所证实(Harlov和Hetherington, 2010; Hetherington等, 2010; Harlov等, 2011; SeydouxGuillaume等, 2012). 例如, Harlov等(2011)在从角闪岩 相到麻粒岩相等不同的 $P-T$ 条件下进行了一系列的实 验, 每一项的实验均包括相对较为均质的独居石 $\left(7 \sim 8 \mathrm{wt} \% \mathrm{ThO}_{2}\right)$ 和不同类型的碱性流体. 结果显示独 居石被部分改造而形成了富 $\mathrm{Th}$ 和 $\mathrm{Si}$ ，但亏损LREE、Y 及 $\mathrm{P}$ 的边部. 该实验中流体实际上起到了催化剂的作 用，交代了独居石并使其被具有新的成分的相同相所 取代(Putnis，2009). 而且经过流体改造后的独居石的 $\mathrm{U}-\mathrm{Th}-\mathrm{Pb}$ 同位素体系也会被重置，并使得独居石不同 的部分具有相近或者不同的年龄(Ayers等, 2002; Seydoux-Guillaume等, 2002; Williams等, 2011; Kelly等, 2012; Sindern等, 2012). 很明显, 本文中独居石的U-Th$\mathrm{Pb}$ 同位素体系被重置了(图6). 此外，上述所举例的受 到流体改造的独居石，其原来的部分和被改造的部分 之间具有尖锐的界限, 本文的独居石也具有这种流体 改造结构(图4). 
上述化学和结构证据表明，威海泥质麻粒岩中的 分带结构独居石的形成机制应与流体对原有独居石的 改造有关. 在混合岩化麻粒岩中, 独居石具有三叠纪年 龄(223.8 \pm 2.9$) \mathrm{Ma}$ 的边部相比于其他部分具有最低的 $\mathrm{Th}(24174 \mathrm{ppm})$ 和 $\mathrm{Pb}(436 \mathrm{ppm})$ 含量(图5d), 但高的HREE (24101ppm)和Y(14502ppm)含量(图7d、8d), 这表明了 其是在独居石重结晶的最后阶段从流体中结晶而成.

需要回答的一个问题是流体从何处而来. 本文研 究的威海泥质麻粒岩呈透镜体状不协调地产出于花岗 质片麻岩中(图1、2). 由于三叠纪深俯冲之后板片折 返时地壳发生的深熔作用, 围岩花岗质片麻岩呈现出 强烈的混合岩化现象(Wallis等，2005; Liu F L等, 2010；Zong等，2010；续海金等，2013；Xu等，2013; Song等，2014). 一般认为深熔作用是由于热折返过程 中含水矿物多硅白云母的分解引起的(Auzanneau等, 2006; Xu等, 2013; Song等, 2014), 之后含水熔体经历 了分离结晶过程继而形成浅色体和富钾长石的伟晶岩 脉. 浅色体中的岩浆锆石给出 $(224 \pm 2) \sim(228 \pm 2) M a$ 的年 龄(Chen等, 2013; Xu等, 2013; 续海金等, 2013). Song等 (2014)和高名迪等(2018)进一步在威海地区识别出了 $(223 \pm 3) \sim(225.9 \pm 2) \mathrm{Ma}$ 的原位富钾长石浅色体. 本研究 中独居石暗灰色的边部给出的 $(223.8 \pm 2.9) \mathrm{Ma}$ 年龄和 部分熔融的时代是一致的. 因此, 混合岩化片麻岩可能 是为麻粒岩透镜体提供碱性流体的潜在源.

\section{3 对苏鲁造山带演化的启示}

厘定泥质麻粒岩的构造亲属性对理解造山带演化 至关重要, 然而其从属问题却一直有着争论. Xiang等 (2014)首次报道了出露于苏鲁造山带内威海地区的古 元古代泥质麻粒岩, 并通过相平衡模拟的方法限定了 其超高温 $\left(>900^{\circ} \mathrm{C}, 11 \sim 13 \mathrm{kbar}\right)$ 变质作用条件, 认为该 麻粒岩从属于扬子克拉通板块的北缘. Xu等(2019)通 过锆石 $\mathrm{Ti}$ 含量温度计方法进一步限定了其变质 $P-T$ 条 件 $\left((928 \pm 10)^{\circ} \mathrm{C}\right)$, 认为该泥质麻粒岩与胶-辽-吉构造带 具有亲属关系. 因此，该泥质麻粒岩的构造亲属性问 题仍处在争议之中.

古元古代(1.90 2.0Ga)的变质作用在扬子克拉通 北缘有广泛的发育(Zhang和Zheng, 2013), 包括崆岭杂 岩体中的混合岩、变沉积岩、片麻岩、角闪岩和麻粒 岩(Zhang等，2006；Wu等，2009)以及黄土岭的高温麻 粒岩(Chen等, 2006; Wu等, 2008). 但是这些变质事件
均明显早于本研究麻粒岩相变质作用事件 (1818 1836Ma). 苏鲁造山带中出露的超高压变质岩包 括花岗质片麻岩、榴辉岩、大理岩、石榴石橄榄岩等 指示了一次三叠纪的变质事件(Zhang等, 1994; Kato 等, 1997; Ye等, 2000b; Liu等, 2008). 然而, 造山带内 的古元古代 $(1.8 \mathrm{Ga})$ 的记录却很少, 而且构造亲属性 存在着争议. 例如, 海阳所杂岩体中 $1.8 \sim 1.86 \mathrm{Ga}$ 的花岗 质片麻岩和基性麻粒岩以及文登地区出露的 $1.8 \mathrm{Ga}$ 的 基性麻粒岩均被认为属于华北克拉通的一部分(Zhai 等, 2000; Liou等, 2006; Liu等, 2017; Feng等, 2020).

胶北地体属于华北克拉通东地块古元古代胶-辽吉带的南段部分，与苏鲁造山带以五莲-烟台断裂为 界(Zhao等, 2012; Tian等, 2017). 不同于苏鲁造山带, 在胶北地体中广泛发育有古元古代岩浆作用和变质 作用. 例如, 栖霞地区出露的角闪岩具有 $1.76 \sim 1.83 \mathrm{Ga}$ 的变质年龄(Tang等, 2007; Wu M L等, 2014), 胶北地 体中高压基性麻粒岩和泥质麻粒岩经历了 1.8 1.84Ga 的高温麻粒岩相变质作用叠加(Tang等, 2007; Zhou等, 2008; Tam等, 2011, 2012b; Zou等, 2017), 并被认为与 同期的A型花岗岩的侵位有关(蔡剑辉等，2002； Li和 Zhao, 2007; Tam等, 2011, 2012a; Liu F L等, 2014; Liu $\mathrm{J} \mathrm{H}$ 等, 2014). 在胶-辽-吉带(Cai等, 2020)和华北克拉 通(Ma等, 2019; Wei等, 2019)中同样记录有古元古代 的超高温变质作用事件. 午极地区的花岗质片麻岩中 岩浆锆石记录了 1.83Ga的年龄代表了该时期的岩浆 作用事件(Zhang等, 2014). 因此, 本研究泥质麻粒岩记 录的变质事件和胶-辽-吉带中的岩浆和变质事件是同 时期的.

泥质麻粒岩与华北克拉通具有亲属性的其他可靠 证据包括: (1) 麻粒岩透镜体的产状和其围岩花岗质片 麻岩的产状是不一致的，这表明了二者的关系只是机 械性的混合; (2) 锆石和独居石是可以用来重建构造 热事件过程的重要工具, 尤其独居石可以在广泛的条 件下生长，继而可以记录多期次年龄信息(Högdahl等, 2012；Bhowmik等，2014; Wu等，2014; Lei等，2020), 但是泥质麻粒岩中的独居石(本研究)和锆石(之前的研 究)只记录了 $1.8 \mathrm{Ga}$ 的变质年龄(图6、10), 并没有任何 新元古代岩浆作用事件记录; (3) 锆石Hf同位素结果表 明本研究的四类岩性具有相同的原岩, 即晚太古代 $(2.7 \sim 2.8 \mathrm{Ga})$ 的地壳物质，且其指示的该期次的地壳生 长和华北克拉通的主要的地壳生长期次是一致的(详 
见熊志武等, 2021). 综上所述, 威海的泥质麻粒岩具有 华北克拉通属性.

对海阳所杂岩体的研究表明，该杂岩体中的基性 麻粒岩对于苏鲁地体来说是外来的, 且来自于胶-辽吉变质带, 在三叠纪大陆碰撞过程中被卷入了俯冲隧 道之中(Liu等，2017; Feng等，2020). Xu和Zhang (2018)报道了北大别地体中的混合岩记录了 $2.5 \mathrm{Ga}$ 的 岩浆作用事件年龄和 $1.8 \mathrm{Ga}$ 的变质年龄. 这两组年龄 与华北克拉通的演化时间相一致，这些信息表明，大 别-苏鲁造山带在三叠纪大陆碰撞过程中, 不仅有大量 的扬子陆壳的物质, 也有华北克拉通物质的卷入. 结合 本文对独居石的研究，我们总结认为威海地区的泥质 麻粒岩应属于华北克拉通物质，由于三叠纪时扬子板 块和华北板块的碰撞作用而被卷入了苏鲁造山带之 中，而后在折返过程中受到了来自发生混合岩化的花 岗质片麻岩的流体改造，从而导致了泥质麻粒岩岩性 的变化.

\section{6 结论}

通过对苏鲁造山带威海地区泥质麻粒岩野外产出 特征、岩相学、独居石U-Pb同位素和微量元素的研 究, 获得主要的认识如下:

(1) 威海泥质麻粒岩从核部到边部岩性逐渐的变 化: 未变形的粗粒泥质麻粒岩、面理化的细粒泥质麻 粒岩、石榴石黑云母片麻岩和混合岩化麻粒岩，均具 有相同的峰期麻粒岩相变质矿物组合: 石榴石 + 斜长 石 $($ 反条纹长石)+石英 + 黑云母+矽线石.

(2) 四类不同岩石中的独居石可以分为两种: 古元 古代( 1.82Ga)的麻粒岩相独居石和三叠纪( 225Ma) 流体改造独居石.

(3) 古元古代麻粒岩相独居石具有HREE和Y亏损, 明显的Eu负异常特征. 在流体的改造作用下原有的独 居石获得 $\mathrm{Th}$ 和 $\mathrm{Si}$ 但释放出U、HREE和P，此改造过程 导致了三叠纪新生独居石具有高的HREE和Y含量, 低 的 $T h$ 和 $U$ 含量及低的 $T h / U$ 值.

(4) 古元古代泥质麻粒岩应与华北克拉通具有亲 属关系, 在三叠纪大陆碰撞过程中卷入苏鲁造山带内, 之后受到了流体的改造.
聪博士在独居石BSE和LA-ICP-MS分析中给予的帮助。 魏春景教授和若名审稿人的建设性意见和建议，对论文 的改进和完善具有重要意义。

\section{参考文献}

蔡剑辉, 阎国翰, 牟保否, 许保良, 邵宏翔, 许荣华. 2002. 辽宁盖县梁 屯-矿铜沟碱性正长岩杂岩体的 U-Pb 和 Sm- $\mathrm{Nd}$ 年龄及其地质意 义. 岩石学报, 18: 349-354

从柏林, 王清晨. 1999. 大别山-苏鲁超高压变质带研究的最新进展. 科学通报, 44: 1127-1141

高名迪, 续海金, 章军锋, 陈辉. 2018. 深俯冲陆壳部分熔融初始熔体 的厘定：来自苏鲁超高压地体混合岩中浅色体证据. 岩石学报, 34: $547-566$

刘福来, 薛怀民, 刘平华. 2009. 苏鲁超高压岩石部分熔融时间的准 确限定：来自含黑云母花岗岩中锆石U-Pb定年、REE和Lu-Hf同 位素的证据. 岩石学报, 25: 1039-1055

熊志武, 续海金, 王攀, 章军锋, 刘强. 2021. 苏鲁造山带威海古元古 代泥质麻粒岩锆石U-Pb年龄和 $\mathrm{Hf}$ 同位素特征及其构造属性. 地 球科学, 46: 504-526

续海金, 宋衍茹, 叶凯. 2013. 苏鲁超高压地体部分熔融时间的厘定: 荣成花岗质片麻岩中浅色条带的锆石U-Pb定年、微量元素和 Lu-Hf同位素证据. 岩石学报, 29: 1594-1606

翟明国, 刘文军. 2001. 麻粒岩的形成及其对大陆地壳演化的贡献. 岩石学报, 17: 28

Aleinikoff J N, Schenck W S, Plank M O, Srogi L, Fanning C M, Kamo S L, Bosbyshell H. 2006. Deciphering igneous and metamorphic events in high-grade rocks of the Wilmington Complex, Delaware: Morphology, cathodoluminescence and backscattered electron zoning, and SHRIMP U-Pb geochronology of zircon and monazite. Geol Soc Am Bull, 118: 39-64

Ames L, Zhou G Z, Xiong B C. 1996. Geochronology and isotopic character of ultrahigh-pressure metamorphism with implications for collision of the Sino-Korean and Yangtze cratons, central China. Tectonics, 15: 472-489

Auzanneau E, Vielzeuf D, Schmidt M W. 2006. Experimental evidence of decompression melting during exhumation of subducted continental crust. Contrib Mineral Petrol, 152: 125-148

Ayers J C, Dunkle S, Gao S, Miller C F. 2002. Constraints on timing of peak and retrograde metamorphism in the Dabie Shan UltrahighPressure Metamorphic Belt, east-central China, using U-Th-Pb dating of zircon and monazite. Chem Geol, 186: 315-331

Bhowmik S K, Wilde S A, Bhandari A, Sarbadhikari A B. 2014. Zoned monazite and zircon as monitors for the thermal history of granulite terranes: An example from the Central Indian Tectonic Zone. J Petrol, 55: 585-621 
Brown M, Johnson T. 2019. Time's arrow, time's cycle: Granulite metamorphism and geodynamics. Min Mag, 83: 323-338

Buick I S, Clark C, Rubatto D, Hermann J, Pandit M, Hand M. 2010. Constraints on the Proterozoic evolution of the Aravalli-Delhi Orogenic belt (NW India) from monazite geochronology and mineral trace element geochemistry. Lithos, 120: 511-528

Cai J, Liu F L, Liu C H. 2020. A unique Paleoproterozoic HP-UHT metamorphic event recorded by the Bengbu mafic granulites in the southwestern Jiao-Liao-Ji Belt, North China Craton. Gondwana Res, 80: $244-274$

Chen Y, Ye K, Liu J B, Sun M. 2006. Multistage metamorphism of the Huangtuling granulite, Northern Dabie Orogen, eastern China: Implications for the tectonometamorphic evolution of subducted lower continental crust. J Metamorph Geol, 24: 633-654

Chen Y X, Zheng Y F, Hu Z C. 2013. Synexhumation anatexis of ultrahigh-pressure metamorphic rocks: Petrological evidence from granitic gneiss in the Sulu orogen. Lithos, 156-159: 69-96

Cherniak D J, Pyle J M. 2008. Th diffusion in monazite. Chem Geol, 256: $52-61$

Cherniak D J, Watson E B. 2001. Pb diffusion in zircon. Chem Geol, 172: $5-24$

Cherniak D J, Watson E B, Grove M, Harrison T M. 2004. Pb diffusion in monazite: A combined RBS/SIMS study. Geochim Cosmochim Acta, 68: 829-840

Dumond G, Goncalves P, Williams M L, Jercinovic M J. 2015. Monazite as a monitor of melting, garnet growth and feldspar recrystallization in continental lower crust. J Metamorph Geol, 33: 735-762

Ernst W G, Tsujimori T, Zhang R, Liou J G. 2007. Permo-Triassic collision, subduction-zone metamorphism, and tectonic exhumation along the East Asian Continental Margin. Annu Rev Earth Planet Sci, 35: 73-110

Feng P, Wang L, Brown M, Wang S, Li X. 2020. Separating multiple episodes of partial melting in polyorogenic crust: An example from the Haiyangsuo complex, northern Sulu belt, eastern China. GSA Bull, 132: 1235-1256

Förster H J. 1998. The chemical composition of REE-Y-Th-U-rich accessory minerals in peraluminous granites of the ErzgebirgeFichtelgebirge region, Germany; Part I, The monazite-(Ce)brabantite solid solution series. Am Miner, 83: 259-272

Foster G, Gibson H D, Parrish R, Horstwood M, Fraser J, Tindle A. 2002. Textural, chemical and isotopic insights into the nature and behaviour of metamorphic monazite. Chem Geol, 191: 183-207

Gardés E, Jaoul O, Montel J M, Seydoux-Guillaume A M, Wirth R. 2006. $\mathrm{Pb}$ diffusion in monazite: An experimental study of interdiffusion. Geochim Cosmochim Acta, 70: 2325-2336
Gibson H D, Carr S D, Brown R L, Hamilton M A. 2004. Correlations between chemical and age domains in monazite, and metamorphic reactions involving major pelitic phases: An integration of ID-TIMS and SHRIMP geochronology with Y-Th-U X-ray mapping. Chem Geol, 211: 237-260

Guergouz C, Martin L, Vanderhaeghe O, Thébaud N, Fiorentini M. 2018. Zircon and monazite petrochronologic record of prolonged amphibolite to granulite facies metamorphism in the Ivrea-Verbano and Strona-Ceneri Zones, NW Italy. Lithos, 308: 1-18

Harley S L, Nandakumar V. 2014. Accessory mineral behaviour in granulite migmatites: A case study from the Kerala Khondalite Belt, India. J Petrol, 55: 1965-2002

Harlov D E, Hetherington C J. 2010. Partial high-grade alteration of monazite using alkali-bearing fluids: Experiment and nature. Am Miner, 95: 1105-1108

Harlov D E, Wirth R, Hetherington C J. 2011. Fluid-mediated partial alteration in monazite: The role of coupled dissolution-reprecipitation in element redistribution and mass transfer. Contrib Mineral Petrol, 162: 329-348

Hermann J, Rubatto D. 2003. Relating zircon and monazite domains to garnet growth zones: Age and duration of granulite facies metamorphism in the Val Malenco lower crust. J Metamorph Geol, 21: $833-852$

Hetherington C J, Harlov D E, Budzyń B. 2010. Experimental metasomatism of monazite and xenotime: Mineral stability, REE mobility and fluid composition. Miner Petrol, 99: 165-184

Högdahl K, Majka J, Sjöström H, Nilsson K P, Claesson S, Konečný P. 2012. Reactive monazite and robust zircon growth in diatexites and leucogranites from a hot, slowly cooled orogen: Implications for the Palaeoproterozoic tectonic evolution of the central Fennoscandian Shield, Sweden. Contrib Mineral Petrol, 163: 167-188

Hu Z C, Zhang W, Liu Y S, Gao S, Li M, Zong K Q, Chen H H, Hu S H. 2015. "Wave" signal smoothing and mercury removing device for laser ablation quadrupole and multiple collector ICP-MS analysis: Application to lead isotope analysis. Anal Chem, 87: 1152-1157

Jiao S J, Guo J H, Harley S L, Peng P. 2013. Geochronology and trace element geochemistry of zircon, monazite and garnet from the garnetite and/or associated other high-grade rocks: Implications for Palaeoproterozoic tectonothermal evolution of the Khondalite Belt, North China Craton. Precambrian Res, 237: 78-100

Johnson T E, Clark C, Taylor R J M, Santosh M, Collins A S. 2015. Prograde and retrograde growth of monazite in migmatites: An example from the Nagercoil Block, southern India. Geosci Front, 6: 373-387

Kato T, Enami M, Zhai M. 1997. Ultra-high-pressure (UHP) marble 
and eclogite in the Su-Lu UHP terrane, eastern China. J Metamorph Geol, 15: 169-182

Kelly N M, Harley S L, Möller A. 2012. Complexity in the behavior and recrystallization of monazite during high- $T$ metamorphism and fluid infiltration. Chem Geol, 322-323: 192-208

Lasalle S, Dunning G, Indares A. 2014. In situ LA-ICP-MS dating of monazite from aluminous gneisses: Insights on the tectonometamorphic history of a granulite-facies domain in the central Grenville Province. Can J Earth Sci, 51: 558-572

Lei H C, Xiang H, Zhang Z M, Qi M, Dong X, Lin Y H. 2014. Paleoproterozoic UHT granulite in the Sulu orogen and its tectonic implications (in Chinese). Acta Petrol Sin, 30: 2435-2445

Lei H C, Xu H J, Xiang H. 2020. Basement evolution of the Sulu orogenic belt: Constraints on zircon U-Pb ages and trace elements from the Weihai gneisses. Geol J, 55: 2646-2661

Li S Z, Zhao G C. 2007. SHRIMP U-Pb zircon geochronology of the Liaoji granitoids: Constraints on the evolution of the Paleoproterozoic Jiao-Liao-Ji belt in the Eastern Block of the North China Craton. Precambrian Res, 158: 1-16

Liou J G, Tsujimori T, Chu W, Zhang R Y, Wooden J L. 2006. Protolith and metamorphic ages of the Haiyangsuo complex, eastern China: A non-UHP exotic tectonic slab in the Sulu ultrahigh-pressure terrane. Mineral Petrol, 88: 207-226

Liu F L, Gerdes A, Zeng L S, Xue H M. 2008. SHRIMP U-Pb dating, trace elements and the Lu-Hf isotope system of coesite-bearing zircon from amphibolite in the SW Sulu UHP terrane, eastern China. Geochim Cosmochim Acta, 72: 2973-3000

Liu F L, Liou J G. 2011. Zircon as the best mineral for $P$ - $T$-time history of UHP metamorphism: A review on mineral inclusions and U-Pb SHRIMP ages of zircons from the Dabie-Sulu UHP rocks. J Asian Earth Sci, 40: 1-39

Liu F L, Liu L S, Liu P H, Wang F, Cai J, Liu J H, Wang W, Ji L. 2017. A relic slice of archean-early Paleoproterozoic basement of Jiaobei Terrane identified within the Sulu UHP belt: Evidence from protolith and metamorphic ages from meta-mafic rocks, TTGgranitic gneisses, and metasedimentary rocks in the Haiyangsuo region. Precambrian Res, 303: 117-152

Liu F L, Liu P H, Wang F, Liu J H, Meng E, Cai J, Shi J R. 2014. U-Pb dating of zircons from granitic leucosomes in migmatites of the Jiaobei Terrane, southwestern Jiao-Liao-Ji Belt, North China Craton: Constraints on the timing and nature of partial melting. Precambrian Res, 245: 80-99

Liu F L, Robinson P T, Gerdes A, Xue H M, Liu P H, Liou J G. 2010. Zircon $\mathrm{U}-\mathrm{Pb}$ ages, REE concentrations and $\mathrm{Hf}$ isotope compositions of granitic leucosome and pegmatite from the north Sulu UHP terrane in China: Constraints on the timing and nature of partial melting. Lithos, 117: 247-268

Liu F L, Robinson P T, Liu P H. 2012. Multiple partial melting events in the Sulu UHP terrane: Zircon U-Pb dating of granitic leucosomes within amphibolite and gneiss. J Metamorph Geol, 30: 887-906

Liu F L, Xu Z Q, Katayama I, Yang J S, Maruyama S, Liou J G. 2001. Mineral inclusions in zircons of para- and orthogneiss from pre-pilot drillhole CCSD-PP1, Chinese Continental Scientific Drilling Project. Lithos, 59: 199-215

Liu F L, Xu Z Q, Xue H M. 2004. Tracing the protolith, UHP metamorphism, and exhumation ages of orthogneiss from the SW Sulu terrane (eastern China): SHRIMP U-Pb dating of mineral inclusion-bearing zircons. Lithos, 78: 411-429

Liu J H, Liu F L, Ding Z J, Liu P H, Guo C L, Wang F. 2014. Geochronology, petrogenesis and tectonic implications of Paleoproterozoic granitoid rocks in the Jiaobei Terrane, North China Craton. Precambrian Res, 255: 685-698

Liu Y S, Gao S, Hu Z C, Gao C G, Zong K Q, Wang D B. 2010. Continental and oceanic crust recycling-induced melt-peridotite interactions in the trans-north China Orogen: $\mathrm{U}-\mathrm{Pb}$ dating, $\mathrm{Hf}$ isotopes and trace elements in zircons from mantle xenoliths. J Petrol, 51: 537-571

Ludwig K R. 2003. ISOPLOT 3.00: A Geochronological Toolkit for Microsoft Excel. California: Berkeley Geochronology Center

Ma S T, Li X P, Liu H, Kong F M, Wang H. 2019. Ultrahigh temperature metamorphic record of pelitic granulites in the Huangtuyao area of the Huai'an Complex, North China Craton. J Earth Sci, 30: 1178-1196

McFarlane C R M, Harrison T M. 2006. Pb-diffusion in monazite: Constraints from a high- $T$ contact aureole setting. Earth Planet Sci Lett, 250: 376-384

Mottram C M, Warren C J, Regis D, Roberts N M W, Harris N B W, Argles T W, Parrish R R. 2014. Developing an inverted Barrovian sequence: Insights from monazite petrochronology. Earth Planet Sci Lett, 403: 418-431

O'Brien P J. 2000. The fundamental Variscan problem: Hightemperature metamorphism at different depths and high-pressure metamorphism at different temperatures. Geol Soc Lond Spec Publ, 179: $369-386$

Poitrasson F, Chenery S, Bland D J. 1996. Contrasted monazite hydrothermal alteration mechanisms and their geochemical implications. Earth Planet Sci Lett, 145: 79-96

Putnis A. 2009. Mineral replacement reactions. Rev Mineral Geochem, 70: $87-124$

Rasmussen B, Fletcher I R, Muhling J R. 2007. In situ U-Pb dating and element mapping of three generations of monazite: Unravelling cryptic tectonothermal events in low-grade terranes. Geochim 
Cosmochim Acta, 71: 670-690

Rasmussen B, Muhling J R. 2007. Monazite begets monazite: Evidence for dissolution of detrital monazite and reprecipitation of syntectonic monazite during low-grade regional metamorphism. Contrib Mineral Petrol, 154: 675-689

Rasmussen B, Muhling J R. 2009. Reactions destroying detrital monazite in greenschist-facies sandstones from the Witwatersrand basin, South Africa. Chem Geol, 264: 311-327

Rubatto D, Hermann J, Buick I S. 2006. Temperature and bulk composition control on the growth of monazite and zircon during low-pressure anatexis (Mount Stafford, Central Australia). J Petrol, 47: 1973-1996

Rubatto D, Williams I S, Buick I S. 2001. Zircon and monazite response to prograde metamorphism in the Reynolds Range, Central Australia. Contrib Mineral Petrol, 140: 458-468

Seydoux-Guillaume A M, Montel J M, Bingen B, Bosse V, de Parseval P, Paquette J L, Janots E, Wirth R. 2012. Low-temperature alteration of monazite: Fluid mediated coupled dissolution-precipitation, irradiation damage, and disturbance of the $\mathrm{U}-\mathrm{Pb}$ and $\mathrm{Th}-\mathrm{Pb}$ chronometers. Chem Geol, 330-331: 140-158

Seydoux-Guillaume A M, Paquette J L, Wiedenbeck M, Montel J M, Heinrich W. 2002. Experimental resetting of the U-Th-Pb systems in monazite. Chem Geol, 191: 165-181

Sindern S, Gerdes A, Ronkin Y L, Dziggel A, Hetzel R, Schulte B A. 2012. Monazite stability, composition and geochronology as tracers of Paleoproterozoic events at the eastern margin of the East European Craton (Taratash complex, Middle Urals). Lithos, 132133: 82-97

Song Y R, Xu H J, Zhang J F, Wang D Y, Liu E D. 2014. Synexhumation partial melting and melt segregation in the Sulu UHP terrane: Evidences from leucosome and pegmatitic vein of migmatite. Lithos, 202-203: 55-75

Sun S S, McDonough W F. 1989. Chemical and isotopic systematics of oceanic basalts: Implications for mantle composition and processes. Geol Soc Lond Spec Publ, 42: 313-345

Tam P Y, Zhao G C, Liu F L, Zhou X W, Sun M, Li S Z. 2011. Timing of metamorphism in the Paleoproterozoic Jiao-Liao-Ji Belt: New SHRIMP U-Pb zircon dating of granulites, gneisses and marbles of the Jiaobei massif in the North China Craton. Gondwana Res, 19: $150-162$

Tam P Y, Zhao G C, Sun M, Li S Z, lizuka Y, Ma G S K I, Yin C Q, He Y H, Wu M L. 2012a. Metamorphic $P-T$ path and tectonic implications of medium-pressure pelitic granulites from the Jiaobei massif in the Jiao-Liao-Ji Belt, North China Craton. Precambrian Res, 220-221: 177-191

Tam P Y, Zhao G C, Sun M, Li S Z, Wu M L, Yin C Q. 2012b.
Petrology and metamorphic $P-T$ path of high-pressure mafic granulites from the Jiaobei massif in the Jiao-Liao-Ji Belt, North China Craton. Lithos, 155: 94-109

Tang J, Zheng Y F, Wu Y B, Gong B, Liu X M. 2007. Geochronology and geochemistry of metamorphic rocks in the Jiaobei terrane: Constraints on its tectonic affinity in the Sulu orogen. Precambrian Res, 152: 48-82

Tang J, Zheng Y F, Wu Y B, Gong B, Zha X P, Liu X M. 2008. Zircon $\mathrm{U}-\mathrm{Pb}$ age and geochemical constraints on the tectonic affinity of the Jiaodong terrane in the Sulu orogen, China. Precambrian Res, 161: $389-418$

Taylor R J M, Clark C, Fitzsimons I C W, Santosh M, Hand M, Evans N, McDonald B. 2014. Post-peak, fluid-mediated modification of granulite facies zircon and monazite in the Trivandrum Block, southern India. Contrib Mineral Petrol, 168: 1044

Tian Z H, Liu F L, Windley B F, Liu P H, Wang F, Liu C H, Wang W, Cai J, Xiao W J. 2017. Polyphase structural deformation of low- to medium-grade metamorphic rocks of the Liaohe Group in the JiaoLiao-Ji Orogenic Belt, North China Craton: Correlations with tectonic evolution. Precambrian Res, 303: 641-659

Wallis S, Tsuboi M, Suzuki K, Fanning M, Jiang L L, Tanaka T. 2005. Role of partial melting in the evolution of the Sulu (eastern China) ultrahigh-pressure terrane. Geology, 33: 129-132

Wang J M, Wu F Y, Rubatto D, Liu S R, Zhang J J, Liu X C, Yang L. 2017. Monazite behaviour during isothermal decompression in pelitic granulites: A case study from Dinggye, Tibetan Himalaya. Contrib Mineral Petrol, 172: 81

Wei G D, Kong F M, Liu H, Wang X M, Zhang Y C, Liu X H. 2019. Petrology, metamorphic $P-T$ paths and zircon $\mathrm{U}-\mathrm{Pb}$ ages for Paleoproterozoic mafic granulites from Xuanhua, North China Craton. J Earth Sci, 30: 1197-1214

Weinberg R F, Wolfram L C, Nebel O, Hasalová P, Závada P, Kylander-Clark A R C, Becchio R. 2020. Decoupled U-Pb date and chemical zonation of monazite in migmatites: The case for disturbance of isotopic systematics by coupled dissolution-reprecipitation. Geochim Cosmochim Acta, 269: 398-412

Williams M L, Jercinovic M J, Harlov D E, Budzyń B, Hetherington C J. 2011. Resetting monazite ages during fluid-related alteration. Chem Geol, 283: 218-225

Williams M L, Jercinovic M J, Hetherington C J. 2007. Microprobe monazite geochronology: Understanding geologic processes by integrating composition and chronology. Annu Rev Earth Planet Sci, 35: $137-175$

Wu M L, Zhao G C, Sun M, Li S Z, Bao Z A, Tam P Y, Eizenhöefer P R, He Y. 2014. Zircon U-Pb geochronology and Hf isotopes of major lithologies from the Jiaodong Terrane: Implications for the 
crustal evolution of the Eastern Block of the North China Craton. Lithos, 190-191: 71-84

Wu Y B, Gao S, Gong H J, Xiang H, Jiao W F, Yang S H, Liu Y S, Yuan H L. 2009. Zircon U-Pb age, trace element and $\mathrm{Hf}$ isotope composition of Kongling terrane in the Yangtze Craton: Refining the timing of Palaeoproterozoic high-grade metamorphism. J Metamorph Geol, 27: 461-477

Wu Y B, Wang H, Gao S, Hu Z C, Liu X C, Gong H J. 2014. LA-ICPMS monazite $\mathrm{U}-\mathrm{Pb}$ age and trace element constraints on the granulite-facies metamorphism in the Tongbai orogen, central China. J Asian Earth Sci, 82: 90-102

Wu Y B, Zheng Y F. 2004. Genesis of zircon and its constraints on interpretation of U-Pb age. Chin Sci Bull, 49: 1554-1569

Wu Y B, Zheng Y F, Gao S, Jiao W F, Liu Y S. 2008. Zircon U-Pb age and trace element evidence for Paleoproterozoic granulite-facies metamorphism and Archean crustal rocks in the Dabie Orogen. Lithos, 101: 308-322

Xiang H, Zhang Z M, Lei H C, Qi M, Dong X, Wang W, Lin Y H. 2014. Paleoproterozoic ultrahigh-temperature pelitic granulites in the northern Sulu orogen: Constraints from petrology and geochronology. Precambrian Res, 254: 273-289

Xu H J, Lei H C, Xiong Z W, Zhang J F. 2019. Paleoproterozoic ultrahigh-temperature granulite-facies metamorphism in the Sulu orogen, eastern China: Evidence from zircon and monazite in the pelitic granulite. Precambrian Res, 333: 105430

Xu H J, Ye K, Song Y R, Chen Y, Zhang J F, Liu Q, Guo S. 2013. Prograde metamorphism, decompressional partial melting and subsequent melt fractional crystallization in the Weihai migmatitic gneisses, Sulu UHP terrane, eastern China. Chem Geol, 341: 16-37

Xu H J, Ye K, Zhang J F. 2012. Temperature of prograde metamorphism, decompressional partial melting and subsequent melt fractional crystallization in the Weihai migmatitic gneisses, Sulu UHP terrane: Constraints from Ti-in-Zircon thermometer. J Earth Sci, 23: 813-827

Xu H J, Zhang J F. 2018. Zircon geochronological evidence for participation of the North China Craton in the protolith of migmatite of the North Dabie Terrane. J Earth Sci, 29: 30-42

Xu S, Liu Y, Chen G, Compagnoni R, Rolfo F, He M, Liu H. 2003. New finding of micro-diamonds in eclogites from Dabie-Sulu region in central-eastern China. Chin Sci Bull, 48: 988-994

Xu S T, Su W, Liu Y C, Jiang L L, Ji S Y, Okay A I, Sengör A M C. 1992. Diamond from the Dabie Shan metamorphic rocks and its implication for tectonic setting. Science, 256: 80-82

Yang J S, Wooden J L, Wu C L, Liu F L, Xu Z Q, Shi R D, Katayama I, Liou J G, Maruyama S. 2003. SHRIMP U-Pb dating of coesitebearing zircon from the ultrahigh-pressure metamorphic rocks, Sulu terrane, east China. J Metamorph Geol, 21: 551-560

Ye K, Cong B L, Ye D N. 2000a. The possible subduction of continental material to depths greater than $200 \mathrm{~km}$. Nature, 407: 734-736

Ye K, Yao Y P, Katayama I, Cong B L, Wang Q C, Maruyama S. 2000b. Large areal extent of ultrahigh-pressure metamorphism in the Sulu ultrahigh-pressure terrane of East China: New implications from coesite and omphacite inclusions in zircon of granitic gneiss. Lithos, 52: 157-164

Zhai M G, Cong B L, Guo J H, Liu W J, Li Y G, Wang Q C. 2000. Sm$\mathrm{Nd}$ geochronology and petrography of garnet pyroxene granulites in the northern Sulu region of China and their geotectonic implication. Lithos, 52: 23-33

Zhang J, Zhao Z F, Zheng Y F, Dai M N. 2010. Postcollisional magmatism: Geochemical constraints on the petrogenesis of Mesozoic granitoids in the Sulu orogen, China. Lithos, 119: 512536

Zhang R Y, Liou J G, Cong B L. 1994. Petrogenesis of garnet-bearing ultramafic rocks and associated eclogites in the Su-Lu ultrahigh- $P$ metamorphic terrane, eastern China. J Metamorph Geol, 12: 169186

Zhang S B, Tang J, Zheng Y F. 2014. Contrasting Lu-Hf isotopes in zircon from Precambrian metamorphic rocks in the Jiaodong Peninsula: Constraints on the tectonic suture between North China and South China. Precambrian Res, 245: 29-50

Zhang S B, Zheng Y F. 2013. Formation and evolution of Precambrian continental lithosphere in South China. Gondwana Res, 23: 12411260

Zhang S B, Zheng Y F, Wu Y B, Zhao Z F, Gao S, Wu F Y. 2006. Zircon $\mathrm{U}-\mathrm{Pb}$ age and Hf-O isotope evidence for Paleoproterozoic metamorphic event in South China. Precambrian Res, 151: 265-288

Zhang Z M, Shen K, Wang J L, Dong H L. 2009. Petrological and geochronological constraints on the formation, subduction and exhumation of the continental crust in the southern Sulu orogen, eastern-central China. Tectonophysics, 475: 291-307

Zhao G C, Cawood P A, Li S Z, Wilde S A, Sun M, Zhang J, He Y H, Yin C Q. 2012. Amalgamation of the North China Craton: Key issues and discussion. Precambrian Res, 222-223: 55-76

Zheng Y F. 2008. A perspective view on ultrahigh-pressure metamorphism and continental collision in the Dabie-Sulu orogenic belt. Chin Sci Bull, 53: 3081-3104

Zhou X W, Zhao G C, Wei C J, Geng Y S, Sun M. 2008. EPMA U-Th$\mathrm{Pb}$ monazite and SHRIMP U-Pb zircon geochronology of highpressure pelitic granulites in the Jiaobei massif of the North China Craton. Am J Sci, 308: 328-350

Zhu X K, O’Nions R K. 1999a. Zonation of monazite in metamorphic rocks and its implications for high temperature thermochronology: 
A case study from the Lewisian terrain. Earth Planet Sci Lett, 171: 209-220

Zhu X K, O’Nions R K. 1999b. Monazite chemical composition: Some implications for monazite geochronology. Contrib Mineral Petrol, 137: 351-363

Zong K Q, Liu Y S, Hu Z C, Kusky T, Wang D B, Gao C G, Gao S, Wang J Q. 2010. Melting-induced fluid flow during exhumation of gneisses of the Sulu ultrahigh-pressure terrane. Lithos, 120: 490510

Zou Y, Zhai M G, Santosh M, Zhou L G, Zhao L, Lu J S, Shan H X. 2017. High-pressure pelitic granulites from the Jiao-Liao-Ji Belt, North China Craton: A complete $P-T$ path and its tectonic implications. J Asian Earth Sci, 134: 103-121

(责任编委: 魏春景) 